\title{
LA EXPANSIÓN Y CONSOLIDACIÓN DE LAS CAJAS DE AHORROS EN EL SISTEMA FINANCIERO ESPAÑOL, 1880-1936*
}

\author{
ANGEL PASCUAL MARTÍNEZ SOTO \\ Universidad de Murcia ${ }^{\mathrm{a}}$ \\ JOAQUIM CUEVAS CASAÑA \\ Universidad de Alicante ${ }^{\mathrm{b}}$
}

\begin{abstract}
RESUMEN
Este artículo estudia la evolución de las Cajas de Ahorros en España durante las últimas décadas del siglo XIX y el primer tercio del XX. Analiza los efectos de la regulación e intervención pública sobre el sector, así como la creación de organismos corporativos y representativos del mismo. También se valora y explica la consolidación de las Cajas en el sistema financiero-bancario. Se utiliza la perspectiva regional para detallar procesos y aclarar estrategias de estas entidades, facilitando la comprensión de su proceso de crecimiento. Entre 1880 y 1936, las Cajas lograron asentarse y desempeñar un papel dentro del sistema financiero, ofreciendo servicios adaptados a las demandas de una clientela popular, y ganando terreno frente a la banca privada en algunas ciudades y en los ámbitos agrarios. Finalmente, las Cajas se convirtieron en un instrumento al servicio de las políticas sociales de los gobiernos, especialmente a través de la inversión en deuda pública.
\end{abstract}

Palabras clave: Cajas de Ahorros, sistema financiero, depósitos de ahorro, Montes de Piedad.

\footnotetext{
* Este artículo tiene su origen en una comunicación presentada a la sesión «Instituciones financieras no bancarias» del VII Congreso de la AEHE, Zaragoza, 2001. Los autores quieren agradecer las opiniones y sugerencias recibidas de los evaluadores anónimos y también reconocer las valiosas críticas recibidas de Andrés Hoyo, Gabriel Tortella, Francisco Comín, Lina Gálvez, Ma Teresa Pérez Picazo, Miguel A. Pérez de Perceval, José M. Martínez Carrión y Josep Ma Pons. El trabajo forma parte de un estudio más amplio elaborado con fuentes estadísticas variadas que, por limitaciones de espacio, queda a disposición de los interesados poniéndose en contacto con los autores.

a Departamento Economía Aplicada, Campus de Espinardo, E30100 Murcia, España. apascual@um.es

b Departamento de Análisis Económico Aplicado, Campus de Sant Vicent del Raspeig, Ap. 99, E03080 Alicante, España.xcuevas@ua.es
} 


\begin{abstract}
This paper analyses the evolution of Savings Banks in Spain during the last decades of the $19^{\text {th }}$ century and the first third of the $20^{\text {th }}$ century. The effects of the regulation and public intervention are analysed, as well as the creation of corporative and representative organisms of Savings Banks. It also reviews the consolidation of the Savings Banks in the financial-banking system. The regional focus is applied to show the strategies used by these financial institutions, in order to understand their growth. Between 1880 and 1936 the Savings Banks played an important role in the financial domestic system, adapting their services to their clients' demands. In this way the Savings Banks confronted the private big banking sector in order to attract more clients, mainly middle and working classes in urban and rural areas. Finally Savings Banks became an important instrument of the social policy of governments, especially through the investment in public debt.
\end{abstract}

Keywords: Savings Banks, financial system, savings deposits.

JEL Classification: G21, N23, N24

\title{
1. INTRODUCCIÓN
}

El desarrollo de la literatura financiera de las últimas décadas ha favorecido un mayor conocimiento del papel desempeñado por las Cajas de Ahorros (CCAA en lo sucesivo) y Montes de Piedad (MMPP) en la historia económica y financiera española. Se conocen de forma bastante aproximada los orígenes del sistema de Cajas y Montes, sus fundamentos ideológicos, y el carácter de las operaciones en su primer desarrollo, es decir, durante el siglo XIX y más específicamente hasta la Restauración. Sin embargo, no resulta tan nítido el papel desempeñado por las Cajas en el período de formación del moderno sistema financiero nacional, esto es, durante los últimos años del siglo XIX y el primer tercio del XX11.

\footnotetext{
${ }^{1}$ Son bien conocidos los principales trabajos que han establecido los rasgos históricos de las Cajas de Ahorro y Montes de Piedad, entre los que destacan: Tortella (1974), Titos (1991), (1999) y (2003a), Forniés (1991), Tedde (1991) y (2001), Vellosillo (1989), Martínez Soto (2000) y (2003b), Comín y Torres (2003) y Fernández Sánchez (2003). También existen numerosas monografías locales, aunque su disparidad de criterios y resultados es enorme. El interés por el estudio del ahorro popular es, además, creciente, como lo demuestra su reciente atención en congresos tanto nacionales -VIII Congreso de la AHE, 2005- como internacionales -Savings Banks as Financial Institutions: Role, Performance and Impact, Centre for Business History in Scotland, University of Glasgow, 2001.
} 
Es precisamente en ese punto donde se ubican los objetivos del presente artículo, que se sintetizan en dos. En primer lugar, analizar el impacto de la regulación y la intervención públicas sobre el sector, así como la creación de organismos corporativos y representativos de las Cajas -la Confederación de Cajas de Ahorros Benéficas, CECAB, principalmente. Ésta constituyó no sólo una respuesta organizativa frente a la regulación y a la banca privada -sobre todo a partir de la Ley de Ordenación Bancaria de 1921 y la creación del Consejo Superior Bancario-, sino también un mecanismo de mejora de la gestión financiera de las entidades. La intervención se concretó en la progresiva elaboración de un cuerpo legislativo unificador de las entidades, y el principal objetivo del poder público fue incorporar a las CCAA como entidades colaboradoras de sus políticas sociales, debido a su potencial financiero y a su enorme alcance en términos de clientela. En segundo lugar, se pretende valorar y explicar la consolidación y expansión de las Cajas en el seno del sistema financiero y bancario nacional hasta 1936 -proceso comparable a la del resto de Europa-, así como su singularización como instituciones financieras con fines y operativa específicos -tanto en la vertiente crediticia como de ahorro. Las Cajas de Ahorro crecieron debido a las condiciones de la demanda, en plena expansión durante el período, pero también porque se orientaron hacia un mercado determinado -los grupos sociales con menor renta- que en términos generales no veían satisfechas sus necesidades financieras a través de la banca privada, en especial en el sector primario.

Una vez establecidas las pautas generales del sector, se ha utilizado la perspectiva regional para analizar con detalle algunas de las claves explicativas de su expansión ${ }^{2}$. La elección de la Federación Regional de Levante-que desde 1926 agrupó las Cajas de Ahorro del País Valenciano y Murcia- responde a la existencia de dinámicas económicas y productivas similares, sobre todo en cuanto a las entidades que operaron en los ámbitos agrarios, y a su utilización como campo para el análisis de determinadas variables mediante la utilización de fuentes directas emanadas de las propias entidades.

Se ha dividido el texto en tres partes. Primero se realiza un repaso breve a la principal legislación relativa al sector, haciendo especial hincapié en las razones y resultados de la misma así como en el proceso de asociacionismo de las Cajas. A continuación se repasa la expansión del ahorro popular en España, analizando primero su incidencia sobre el sistema financiero. Posteriormente, la perspectiva regio-

${ }^{2}$ En España la investigación regional ha contribuido a ampliar el conocimiento de los flujos y circuitos financieros en el período de formación del moderno sistema financiero nacional, complementando así los trabajos sobre empresas financieras específicas o de carácter general. Algunos de los primeros trabajos sobre el desarrollo del ahorro popular en España -Tortella (1974); Nadal y Sudrià (1981) - ya analizaron las pautas financieras y del ahorro nacional a través de su incidencia territorial. Esta circunstancia ha favorecido el análisis regional, como se demostró en trabajos posteriores -CECA (1986) y (1987)-, o también en los más recientes: Titos (2003b), García Ruiz (2002), Maixé (2001), y Maixé, Vilar y Lindoso (2003). 
nal permite concretar las pautas territoriales de tal expansión y las estrategias que propiciaron un grado cada vez mayor de captación de ahorro. En tercer y último lugar se analiza la vertiente inversora y crediticia, también desde la óptica nacional y regional, para acabar con las principales conclusiones del trabajo y un anexo estadístico que recoge los principales indicadores relativos al sector obtenidos a través de la depuración de las informaciones disponibles.

Las fuentes existentes para el estudio de las Cajas son muy heterogéneas. Tradicionalmente se han utilizado las estadísticas elaboradas por la Caja de Ahorros y Monte de Piedad de Madrid en sus Memorias Anuales ${ }^{3}$ cuyos problemas de continuidad obligan a realizar ejercicios de tratamiento estadístico de los datos, que no siempre resultan efectivos. Además incluyen entidades que no se corresponden específicamente con las Cajas de Ahorros «benéficas». Otra fuente alternativa la constituyen los trabajos de Ceballos Teresí (1929 y 1932), de los cuales resulta destacable la serie de microhistorias de entidades que presenta. Los Anuarios Financieros ofrecen series sobre los saldos de ahorro de las Cajas, pero no tienen un valor serial uniforme y, a partir de 1927, presentan unas cifras desorbitadas, sin aclarar de dónde procede esa información. De hecho algunos trabajos las han utilizado acríticamente dando lugar a una serie distorsionada a partir de la fecha señalada. También se dispone, a partir de 1929, de las series elaboradas por la CECAB respecto a las entidades confederadas, pero se trata de una fuente incompleta -ya que sólo hace referencia a este grupo- y temporalmente reducida.

Por último están las series y resúmenes de los Anuarios Estadísticos de España, elaborados a partir de la información oficial procedente de los Ministerios que tuvieron en cada momento las competencias sobre estas entidades. En este caso se especifica el número de entidades, el de impositores, así como los saldos de ahorro y su distribución en cada uno de los subsectores -Cajas Benéficas, de la Banca privada y Caja Postal, con informes anuales detallados. Respecto a los MMPP, la información que ofrecen es también significativa, ya que muestra el número de préstamos y el capital prestado. Hemos optado por utilizar esta fuente después de analizar sus discordancias seriales con respecto a las demás, que, en el caso de la más utilizada -las series depuradas a partir de las Memorias de la Caja de Ahorros y Monte de Piedad de Madrid de Tortella (1974) y de Nadal y Sudrià (1983)-, no presentan excesivas desviaciones, salvo en algunos años. Además, sus datos no necesitan de tratamientos estadísticos de ajuste por lagunas de información y recogen con mayor nitidez los diferentes tipos de Cajas -aparte de haber contrastado su alta fiabilidad a través de informaciones directas de entidades, lo que ha permitido depurar y mejorar la serie nacional resultante. Consideramos, pues, que ésta es la mejor fuente para un acercamiento de largo plazo a las Cajas de Ahorro. Para el estudio regional se ha recurrido a fuentes de las propias entidades -memorias y

${ }^{3}$ Tortella (1974); Nadal y Sudrià (1983); Titos (1991) y (1993), entre otros. 
cuentas anuales-, que han servido para analizar algunos aspectos más concretos. También se ha recurrido a diversas publicaciones contemporáneas referentes a cuestiones financieras y bancarias, principalmente al Anuario Financiero de Bilbao, publicado desde 1914 por el Banco de Vizcaya.

Por último, cabe destacar que, para un tratamiento más homogéneo de la evolución temporal, se ha optado por trabajar con precios constantes, utilizando para ello el deflactor de Prados (2000) mediante el PIB al coste de los factores con base en 1935. En ocasiones, sin embargo, se han utilizado precios corrientes, lo que en su caso se advierte, y sólo para presentaciones estáticas concretas.

\section{LAREGULACIÓN PÚBLICADE LAS CAJAS DE AHORROS ESPAÑOLAS, 1880- 1935}

La ordenación de las Cajas de Ahorros estuvo marcada por dos circunstancias: por un lado, la pretensión de los sucesivos gobiernos por aprovechar la potencialidad de estas entidades para contribuir a financiar determinadas políticas sociales y económicas y, por otro, la batalla iniciada por la banca privada para limitar la competencia de las Cajas a la hora del reparto del mercado financiero. En medio de ambas cuestiones, las Cajas respondieron mediante la creación de órganos cuyo objetivo era defender corporativamente sus intereses a través de la cooperación con el poder público y la participación en el diseño de la política financiera. Las principales leyes y normativas de este período pueden sintetizarse en cuatro: Ley de 29 de junio de 1880, Real Decreto-Ley de 9 de abril de 1926, Real Decreto-Ley de 21 de noviembre de 1929, y el Decreto de 14 de marzo de 1933 que creaba el Instituto de Crédito de las Cajas de Ahorros (ICCA). Un breve análisis permite observar el crecimiento progresivo de las Cajas en relación con el desarrollo de la política económica general de la Restauración y la II República.

La Ley de 1880 perseguía diversos fines. El primero de ellos se refiere al compromiso del Gobierno de promocionar la fundación de Cajas de Ahorros en aquellas zonas en las que no existieran, además de «procurar» que los Montes de Piedad permaneciesen unidos a las Cajas para el auxilio recíproco, pero admitiendo la posibilidad de fundar de manera separada ambos organismos, cuestión importante por la mayor libertad de inversión de las entidades ${ }^{4}$. La Ley definía las Cajas como «Instituciones de Beneficencia», con un carácter privado, dependiendo, en parte, de la legislación propia de Beneficencia ${ }^{5}$. Esta configuración les reconocía deter-

${ }^{4}$ Sobre la situación de los Montes de Piedad en la legislación contemporánea, véase Ros Pérez (1996, pp. 85-89). Buena parte de las Cajas fundadas tras la Ley de 1880 ya no llevaron la denominación de Monte de Piedad.

${ }^{5} \mathrm{Al}$ considerarse a las Cajas como «Institutos de Beneficencia» -en la órbita del Ministerio de Gobernación-, pasaban a regularse por la legislación específica en esta materia, en particular los RR.DD. de 1875 y 1885. Un análisis jurídico, en González Moreno (1983, pp. 10 ss.). 
minadas exenciones fiscales y tributarias ${ }^{6}$. El control del Estado sobre las Cajas se realizaría reconociendo su autonomía, reservándose como potestad el examen y aprobación de sus estatutos y reglamentos, y mediante el protectorado sobre las mismas, a través del Ministerio de Gobernación ${ }^{7}$. La legislación de 1880 supuso el primer paso en la configuración de las Cajas como instituciones de carácter social, más allá del papel que les atribuía su carácter benéfico. Este carácter social se reforzó a partir de los estatutos del INP de 1908, que las vincularon como entidades colaboradoras, y por lo tanto partícipes de la política social del Gobierno. A continuación de la Ley se publicó el R. D. de 13-VII-1880 que aprobaba los Estatutos del Monte de Piedad y Caja de Ahorros de Madrid, primera interpretación de esta norma, y en el que se regulaban sus órganos de gobierno y dirección con participación de los poderes públicos.

Fue tras la Primera Guerra Mundial cuando se produjo un mayor grado de intervención pública sobre las entidades de ahorro popular, como por otra parte ocurrió en todos los aspectos de la política económica y financiera. La mayor regulación, paralela a la progresiva concentración del sector bancario durante la década de 1920, fue también patente en el ámbito de las Cajas de Ahorros. En esta dirección actuó el Real Decreto-Ley de 1926, que establecía el Registro e Inspección de las entidades de Ahorro, e incluía la obligatoriedad de inscripción en un Registro que establecería el Ministerio de Trabajo, Comercio e Industria. Las Cajas fueron englobadas junto a otras instituciones -Entidades de Ahorro, Seguros, Mutualidades, etc.-, con lo que la normativa produjo un caos en la situación que intentaba regular. Por primera vez se establecía que sus documentos y libros de contabilidad y auxiliares deberían ajustarse a los requisitos exigidos por el Código de Comercio. También se establecía la obligación de dar determinadas informaciones a los clientes y de publicar con tal fin una memoria anual. El decreto constituía un intento de control del sector, pero, al no ajustarse a la realidad de las instituciones -por ejemplo, se exigía que las entidades de ahorro fuesen sociedades anónimas o mutualidades-, fracasó desde su origen, pues su aplicación hubiera puesto al margen de la legalidad la mayoría de las Cajas. Finalmente, la normativa de 1926 supuso el inicio de la vinculación directa de las Cajas con la política social y financiera del Estado, hecho materializado en el coeficiente de inversión y en la dependencia del Ministerio de Trabajo, Comercio e Industria a través de la Dirección General de Seguros y Ahorro.

\footnotetext{
${ }^{6}$ La inclusión de Cajas y Montes en la categoría de Beneficencia les otorgó los beneficios fiscales establecidos con el R. D. de 14-III-1899: pobreza legal a la hora de litigar en los juzgados y la imposibilidad de embargo. También adquirirían las exenciones fiscales previstas en las normativas de impuestos: art. 17 del Reglamento de la Contribución de Utilidades de 18-IX-1906; art. 14 de la Ley de 28-XII-1910 sobre Contribución Territorial. Estudios específicos sobre estos aspectos se encuentran en Martín-Retortillo (1975, p. 342) y González Moreno (1983, p. 26).

${ }^{7}$ La institución del Protectorado permitía la intervención del poder público en unas entidades privadas basándose en su carácter benéfico, y supuso la vigilancia y tutela del Ministerio de Gobernación en sus actividades.
} 
El desorden que la normativa de 1926 introdujo en el sector provocó una rápida rectificación tres años después mediante el Real Decreto-Ley de 21-XI-1929, que distinguía entre la regulación propia de estas entidades y la correspondiente a otras de carácter puramente privado, a través de sus respectivos «estatutos especiales». Aspecto novedoso constituye la ordenación de los órganos de gobierno de las Cajas, que pasaban a estar regidas por juntas, patronatos o consejos, de carácter social y de actuación gratuita, y fijando el tipo de responsabilidades correspondientes a consejeros, directores o administradores. También se regularon aspectos concretos como los límites de operaciones de activo y pasivo, la obligatoriedad de información a los clientes, el destino cultural y benéfico de los fondos en presunción de abandono, el coeficiente de garantía, las inversiones obligatorias en valores públicos, publicidad de resultados, y los contenidos de los libros de actas y contabilidad, entre otros. Finalmente, la última regulación significativa previa a la guerra civil fue el Decreto de 14-III-1933 que aprobaba el Estatuto de las Cajas Generales de Ahorro Popular y que las definía como:

«Instituciones de Patronato oficial o privado exentas de lucro mercantil, no dependientes de otra empresa, regidas por Juntas o Consejos de actuación gratuita y dedicadas a la administración de depósitos de ahorro de primer grado, con el propósito de invertir los productos si los tuviera, después de descontados los gastos generales, en constituir reservas, sanear el activo, estimular a los imponentes y realizar obras sociales y benéficas». ${ }^{8}$

Esta nueva norma no derogaba el Estatuto de 1929, sino que confirmaba el carácter benéfico-social de las Cajas a través del establecimiento obligatorio de lo que se denominó «obra social, benéfica y cultural» complementaria a su actuación fundamental. Además, se delimitaban sus inversiones con un sentido intensamente social. Se regularon las inversiones obligatorias que debían realizar en fondos públicos nacionales y valores industriales admitidos al efecto, determinándose por el Gobierno en cada caso la proporción de las mismas. Además de ello, el Decreto de 1933 creaba el Instituto de Crédito de las Cajas de Ahorros (ICCA), que integraba a las Cajas que se habían asociado en la Confederación Española de Cajas de Ahorros (CECA). El ICCA, que se convertía en un intermediario entre las Cajas y los organismos públicos que requirieran su asistencia financiera, se creó con plena capacidad jurídica y para actuar como banco de las Cajas, ya que podía apoyar con fondos a aquellas que necesitasen hacer frente a dificultades económicas o bien movilizar su activo. También actuaba como intermediario de éstas en la negociación de valores o en la concurrencia a los empréstitos del Estado. La intermediación abarcaba las labores

${ }^{8}$ Art. $2^{\circ}$ del Estatuto de las Cajas Generales de Ahorro Popular aprobado por el D. de 14-III1933 del Gobierno de la República y firmado por los Ministros de Hacienda, Trabajo y Previsión Social y el de Gobernación. 
de giro y transferencia de fondos y libretas entre las Cajas afiliadas, e incluso tenía la potestad de emitir cédulas con la garantía del patrimonio social de las mismas.

En definitiva, durante los últimos años del siglo XIX y el primer tercio del XX la regulación del ahorro popular en España fue significativa, en consonancia con el resto de los países europeos, que, a excepción de Italia -donde existía una legislación más permisiva en cuanto a la administración y a la colocación de fondos-, observaron un riguroso control público, sobre todo en lo relativo a los límites de las imposiciones y los coeficientes de inversión 9 .

Este esfuerzo de intervención encontró respuesta desde las propias entidades a través de la creación de asociaciones y organismos colectivos tendentes a defender sus intereses corporativos frente al sector público y la banca privada. Así, desde su primera época de funcionamiento, las Cajas de Ahorros mantuvieron entre ellas una relación fluida de carácter informal para el intercambio de información y estímulo recíproco, en la que jugó un papel catalizador la Caja de Madrid ${ }^{10}$. Sin embargo, estos contactos no eran suficientes para presentar interlocutores válidos en defensa de sus intereses y para influir en la elaboración de las disposiciones legales relacionadas con el ahorro. La normativa de 1926 supuso un punto de inflexión en este proceso asociativo, ya que homologaba las Cajas a las Cooperativas, a las Mutualidades y a las Entidades de Previsión -homologación elaborada sin consultar a las primeras, lo que produjo su rechazo. Además, la representación de los bancos privados logró que el Estado prohibiese a las Cajas la realización de operaciones de tipo mercantil, al tiempo que excluía de estas restricciones a las secciones de «Cajas de Ahorros» existentes en algunos de ellos.

Esta situación mostró a los directivos de las Cajas la necesidad de la creación de un organismo de representación de sus intereses, en consonancia con lo que habían llevado a cabo las cajas de ahorros de los países del entorno europeo ${ }^{11}$. En este sentido, el poder alcanzado por la banca privada a través del Consejo Superior Bancario en la determinación de la política financiera de los gobiernos llevó en 1924 a la fundación de la Federación Regional de Cajas de Ahorros Vasco-Navarras, la cual

\footnotetext{
${ }^{9}$ Sobre la regulación de cajas en Europa hasta la Gran Guerra, véanse Gras (1997), Krüger (1997), Americi (1997) y Moss (1997), referidos respectivamente a Italia, Alemania, Francia y Reino Unido. Todos ellos en el volumen conjunto L'Historire des Caisses d'Épargne Européennes.

${ }^{10}$ Es de destacar el papel desempeñado en un primer momento por esta entidad y por su Director-Gerente entre 1873 y 1892, Braulio Antón Ramírez, realizando una eficaz labor de comunicación con el resto de Cajas, cuyo reflejo queda en las Memorias Anuales de esta entidad o en la propia obra de Antón Ramírez (1876).

${ }^{11}$ Existía el ejemplo de Alemania, donde las cajas se habían asociado a escala nacional desde 1884 partiendo de federaciones regionales, así como también el de otros países europeos: Inglaterra (1887), Suecia (1900), Polonia (1902), Austria (1905), Dinamarca (1905), Holanda (1907), Francia (1911) e Italia (1911). Sobre el proceso de asociación de las cajas europeas ver Institut International de l’Épargne (1935, pp. 27-28).
} 
constituyó la primera iniciativa con vistas a presentar un frente unido ante la Asociación de Bancos y Banqueros del Norte de España. Entre sus objetivos se perseguía una mayor unión entre las Cajas y la defensa de sus intereses, así como la creación de instituciones y procedimientos colectivos en favor de los miembros asociados. Este ejemplo tuvo rápida extensión, y, entre 1925 y 1929, se produjo la fundación del resto de federaciones regionales: Galicia (1925); Levante (Castellón, Valencia, Alicante y Murcia), Catalana-Aragonesa-Balear y Oeste (Salamanca, Palencia, Valladolid, Cáceres y Badajoz), todas en 1926; Castellana (Santander, Logroño, Burgos, Soria y Ávila) en 1927; Asturiana y Andaluza (1928), y Canaria (1929).

Este proceso culminó en la Primera Asamblea Ordinaria de 27 de febrero de 1927, en la que se elaboró un proyecto de estatutos de la Confederación Española de Cajas de Ahorros Benéficas (CECAB). La Real Orden de 21-IX-1928 confería el respaldo legal a la CECAB y aprobaba su inscripción en el Registro especial como institución similar y complementaria de los Montes de Piedad y Cajas de Ahorros. Además, quedaba sometida al protectorado del Ministerio de Trabajo y Previsión Social y se le reconocía la representación de las Cajas. El R.D.-Ley de 1929 facultaba a la CECAB para proponer las entidades que debían incorporarse a la Junta Consultiva de Cajas Generales de Ahorro. La regulación jurídica de las federaciones regionales se produjo en el Estatuto de las Cajas Generales de Ahorro Popular de 1933, cerrándose de esta manera el reconocimiento legal de este proceso corporativoasociacionista. En este estatuto se establecía la representación individual o colectiva de las entidades confederadas en asuntos domésticos o de índole internacional, su constitución como centro de estudios en asuntos relativos al ahorro, y su capacidad para mantener relación con las organizaciones semejantes de otras naciones y, especialmente, con el Instituto Internacional del Ahorro ${ }^{12}$.

La política de intervención puesta en marcha por la Dictadura de Primo de Rivera implicó para el sector una toma de conciencia de la necesidad de presentar ante el Estado una imagen clara de sus objetivos, procurando concentrar su poder a través de la integración de las entidades locales en unidades organizativas mayores. Para ello, su principal baza radicaba en la potencialidad de las Cajas como instrumento de apoyo a la política social de los gobiernos. Esto fue evidente sobre todo en materia de construcción de casas baratas, en el desarrollo del ahorro escolar, en la actuación junto con los ayuntamientos y en el régimen de previsión popular. La creación de la CECAB aumentó las potencialidades de las Cajas en este terreno, y entre sus estrategias estuvo el acercamiento y vinculación al Estado. Entre 1928 y 1935, la CECAB y sus Cajas adheridas mantuvieron una relación estable

${ }^{12}$ El Instituto Internacional del Ahorro, posteriormente denominado Instituto Internacional de Cajas de Ahorros (IICE), fue creado en 1925. Su precedente se encuentra en el Primer Congreso Mundial de Cajas de Ahorros celebrado en Milán en 1924, con motivo del primer centenario de la fundación de la Caja de Ahorros milanesa. 
con la Administración a través de la Junta Consultiva del Ahorro, instancia en la cual la Confederación intentó canalizar su influencia en materia legislativa. Por ejemplo, en 1935 las gestiones realizadas por la CECAB ante el ministro Chapaprieta fueron decisivas para hacer frente a las pretensiones de la banca privada de limitar y prohibir a las Cajas la apertura de nuevas sucursales.

Otro aspecto en el que se mostraron las diferencias de intereses entre la banca y las Cajas fue el de la política de tipos de interés del Ministerio de Hacienda y el Banco de España. Estas diferencias se hicieron más evidentes desde 1933, ya que tanto la CECAB como el Consejo Superior Bancario trataron de hacer valer sus influencias para orientar la decisión de la Administración hacia sus posiciones. En términos generales, las Cajas trataron de conseguir unos tipos altos, mientras que los bancos y otros grupos empresariales estaban interesados en que se mantuviesen bajos para alentar la inversión. La cuestión de los tipos de interés debe enmarcarse en el análisis más general de la política económica de los distintos gobiernos republicanos y los problemas a los que debieron hacer frente, sobre todo en relación con la preocupación oficial por el tipo de cambio y la cotización de la peseta ${ }^{13}$. La política monetaria desarrollada desde 1930, considerada como relativamente deflacionista, con unos tipos al alza y un descenso de las líneas de crédito del Banco de España ${ }^{14}$, se conjugó con dos hechos a tener en cuenta. Por un lado, existen numerosos testimonios procedentes de la banca privada que aludían a la dificultad de colocar productivamente los recursos -entre 1930 y 1933, tanto el crédito comercial como los préstamos bancarios descendieron-, y, por otro, la pignoración indirecta de la deuda dejaba en manos de la banca privada una parte del control de la liquidez. En definitiva, la política de tipos resultó otro de los escenarios en los que se escenificó el enfrentamiento entre bancos y Cajas, aunque conviene recordar que la reducción de los tipos de interés desde 1933 fue tan importante para las entidades financieras como la mejora de las expectativas económicas, a tenor de los propios testimonios ${ }^{15}$.

La actuación de la CECAB por lograr la ruptura de las limitaciones financieras establecidas desde el Ministerio de Hacienda y el Consejo Superior Bancario le llevó a implicarse cada vez más en la política social de los gobiernos republicanos. Así, la CECAB se prestó a colaborar en la creación del Banco Nacional Agrario destinado a financiar la reforma agraria, solicitando que las Cajas fuesen sucursales de esta entidad a cambio de conseguir un trato similar

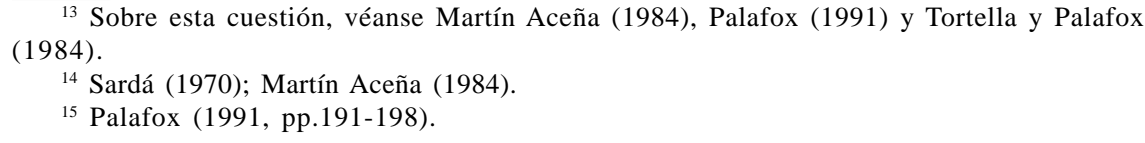


al que disfrutaba la banca privada en materia de hipotecas. También cabe destacar el papel desempeñado por la CECAB ante la petición de colaboración de los Ministerios de Agricultura y Hacienda en el desarrollo del Crédito Agrícola Oficial. Otro objetivo de la Confederación fue su presencia en la política social oficial, como muestra su petición al Ministro de Trabajo de participación en las discusiones sobre los problemas de la vivienda -en 1931 participaba en el II Congreso de Cooperativas de Casas Baratas, obteniendo un puesto en el $\mathrm{Pa}$ tronato de Política Social Inmobiliaria del Estado. También en 1931, el secretario de la CECAB entró a formar parte de la Junta Nacional de Ordenación y Desarrollo de Obras para remediar el Paro Obrero. En resumen, la implicación de la CECAB y de sus Cajas en la política social del Estado fue creciendo entre 1930 y 1935, a la par que ésta conseguía un puesto independiente en el sector del ahorro nacional ${ }^{16}$. El hecho de que reuniera a la mayor parte de las Cajas urbanas explica su peso determinante en el sector. De esta forma, si, en el momento de su constitución (1928), la CECAB agrupaba al 43\% del total de Cajas españolas (74 de 172) y a algo más de la mitad de los depósitos de las mismas (53,6\%), siete años después, en 1935, las proporciones habían variado de forma sensible: aunque la de entidades asociadas descendió ligeramente (al $38 \%$, con 85 sobre 222), los depósitos crecieron hasta concentrar el 72,6\%, con 2.671 millones de pesetas sobre $3.680^{17}$.

\section{LA EXPANSIÓN DE LAS CAJAS DE AHORROS, 1880-1936}

En correspondencia con la evolución institucional y económica del país, durante este período las Cajas se consolidaron y expandieron por todo el territorio, además de ampliar y modernizar sus servicios. Tal expansión arrancó con la Restauración y se acentuó durante el primer tercio del siglo XX, como muestran los datos de número de entidades, imponentes y depósitos de ahorro de estas entidades.

\footnotetext{
${ }^{16}$ Por otra parte, un aspecto no menos importante de la CECAB fue su contribución a la modernización de la gestión de las Cajas a través de cursos de formación destinados a sus directivos y empleados, en los que se exponían contenidos esenciales para la organización de las operaciones, la homogeneización contable, características y modos de inversión, productos financieros, etc. De este modo, la Confederación desempeñó un papel activo en cuanto a la extensión y homologación de las formas de gestión financiera en las Cajas de Ahorro españolas durante el primer tercio del siglo XX.

17 Datos extraidos del Archivo Histórico del Banco de España, Sección Banca Privada, Caja 80, y del AEE de 1935.
} 


\section{CUADRO 1}

NÚMERO DE CAJAS DE AHORROS, IMPONENTES Y DEPÓSITOS DEAHORRO EN ESPAÑA, 1880-1935 (Pesetas constantes de 1935)

\begin{tabular}{|c|c|c|c|c|c|}
\hline & Cajas* & $\begin{array}{c}\text { Imponentes } \\
\mathbf{( A )}\end{array}$ & $\begin{array}{c}\text { Depósitos (B) } \\
\left.\mathbf{( 1 0}^{\mathbf{6}} \mathbf{\text { pts. }}\right)\end{array}$ & $\begin{array}{c}\text { Indice A } \\
\mathbf{( 1 9 0 0 = 1 0 0 )}\end{array}$ & $\begin{array}{c}\text { Indice B } \\
\mathbf{( 1 9 0 0}=\mathbf{1 0 0})\end{array}$ \\
\hline 1880 & 26 & 79.600 & 128,1 & 37,1 & 51,1 \\
1885 & 36 & 110.400 & 160,3 & 51,5 & 63,9 \\
1890 & 43 & 131.300 & 215,6 & 61,2 & 86,0 \\
1895 & 43 & 188.600 & 248,3 & 87,9 & 99,0 \\
1900 & 50 & 214.500 & 250,8 & 100,0 & 100,0 \\
1905 & 72 & 415.100 & 528,9 & 193,5 & 210,9 \\
1910 & 103 & 620.357 & 707,7 & 289,2 & 282,2 \\
1915 & 112 & 836.523 & 805,0 & 390,0 & 321,0 \\
1920 & 112 & 1.521 .467 & $1.316,4$ & 709,3 & 524,9 \\
1925 & 195 & 2.121 .707 & $2.171,2$ & 989,1 & 865,7 \\
1930 & 212 & 3.565 .724 & $3.526,2$ & $1.662,3$ & $1.406,0$ \\
1935 & 222 & 3.680 .105 & $3.975,5$ & $1.715,7$ & $1.585,1$ \\
\hline
\end{tabular}

Fuente: Anuarios Estadísticos de España.

Nota: * Se contabiliza el número de entidades existentes, no el de oficinas o sucursales.

En términos generales, el número de Cajas e imponentes creció muy sensiblemente, sobre todo durante los primeros decenios del siglo XX. A ello contribuyó el moderado pero continuado crecimiento económico de las primeras décadas del siglo $\mathrm{XX}$, que incrementó el nivel general de la renta y permitió aumentar el ahorro familiar. De hecho, el primer impulso fundacional vinculado a iniciativas locales, anterior a 1880, no alcanzó a todas las regiones españolas y, por tanto, tuvo un efecto limitado $^{18}$. La expansión fue mayor en determinadas coyunturas, especialmente en los quinquenios 1905-1909 y durante toda la década de 1920, ralentizándose durante los primeros años de la década de los treinta. Aunque en general no siguieron a la banca privada en la formación de una amplia red de sucursales, ya que este fenómeno fue posterior, algunas de las mayores entidades extendieron sus oficinas más allá de sus lugares de origen -lo que sugiere considerar un cierto sesgo a la baja en

${ }^{18}$ Forniés (1991), Tedde (1991), Titos (1991) y (1993), Vellosillo (1989) y Martínez Soto (2000). 
cuanto al número de Cajas en funcionamiento a partir aproximadamente de $1920^{19}$. Además, a partir de 1916 la red de CCAA se complementó con la fundación de la Caja Postal, que en 1920 ya estaba presente en 49 provincias y tenía alrededor de 355.000 impositores, es decir, casi una cuarta parte del más de millón y medio de cuentas de ahorro de todo el sistema de Cajas. Éste contaba hacia 1935 con casi 3,7 millones de imponentes, lo que suponía más del doble de la cifra existente a comienzos de 1920, y representaba a un tercio de la población total española $(32,2 \%)$. El notable incremento del número de entidades entre 1920 y 1925 guarda relación con la inclusión en la última fecha del conjunto de Cajas bancarias, que, aunque principalmente comenzaron sus operaciones durante los dos primeros decenios del siglo XX, sólo desde principios de la década de 1920 son registradas de manera fiable. En resumen, el éxito de las Cajas de Ahorro en España es comparable, aunque con retraso, al experimentado en el resto de los países europeos. Concretamente, desde Alemania, Francia e Italia provino el mayor impulso del ahorro popular y del cooperativismo, ya que, desde inicios del siglo XIX, los publicistas de esta modalidad de crédito elaboraron los fundamentos económicos y organizativos que después influyeron en España ${ }^{20}$.

En la Europa continental, pero también en Gran Bretaña, hubo una extensión de diferentes formas de cooperativismo y pequeño ahorro durante el último tercio del siglo XIX y primeros años del XX, precisamente hasta la Primera Guerra Mundial. En Alemania, los distintos sistemas existentes -el cooperativismo agrario compuesto por los tres tipos de Cajas Rurales Raiffeisen, Hass y Schulze-Delitzsch, así como las Cajas ordinarias- tendieron a converger operativa y legislativamente después de 1918, en un esfuerzo institucional por coordinar las acciones orientadas a regularizar la situación monetaria ${ }^{21}$. Previamente, sin embargo, los distintos sistemas habían alcanzado una gran difusión por todo el territorio. El impacto de la guerra no impidió su rápida recuperación, y, en 1929, el número de Cajas de Ahorros ordinarias alemanas no vinculadas a una cooperativa agraria alcanzaba las 3.236 instituciones, con cerca de 11.500 oficinas y 7 millones de impositores. En Francia, el mayor impulso de un movimiento iniciado prácticamente desde la revolución francesa se produjo tras los efectos de la crisis finisecular sobre el sector agrícola. Así, en 1902 todo el sistema de cajas francés ya agrupaba a casi 11 millones de imponentes, la mayor

\footnotetext{
${ }^{19}$ Aparte de algunas grandes entidades -Cajas de Madrid y Valencia-, cuyo crecimiento se produjo a través de agencias urbanas, la única caja que creó una red de sucursales fue la Caixa de Pensions. Para ello no sólo creó nuevas oficinas propias, sino que también absorbió a cajas locales, parroquiales y laborales. Además, el crecimiento de la Caixa tuvo estrecha relación con su vinculación al INP. Vid. Nadal y Sudrià (1981, pp. 111-128).

${ }^{20} \mathrm{Al}$ respecto, véanse los trabajos reunidos bajo la dirección de M. Pix y H. Pohl (1993), referidos a la difusión de la idea del ahorro y de las instituciones de ahorro en la Europa del siglo XIX. (2001).

${ }^{21}$ Una valoración del papel de las instituciones de ahorro popular en Alemania, en Guinnane
} 
parte de ellos $(7,2)$ de cajas rurales y urbanas de carácter privado y el resto $(3,5)$ repartido por la red de sucursales de la Caja Nacional (Postal). En Gran Bretaña el fenómeno tuvo también una notoria importancia en cuanto al incremento del número de imponentes, aunque con dos particularidades. Por un lado, el enorme peso de las oficinas de la Caja Postal, que en 1886 contaba con casi 4 millones de imponentes y 8.351 oficinas, y, por otro, el menor peso relativo del ahorro popular en el conjunto del sistema financiero británico, de largo el más desarrollado de Europa durante el siglo XIX. Finalmente, en Italia, cuya evolución influyó sensiblemente en España, el máximo desarrollo se produjo entre 1870 y 1910, tanto en lo que respecta al crecimiento de cajas ordinarias -de orientación católica- como de los bancos populares y cajas bancarias, un modelo rápidamente adoptado en España ${ }^{22}$. El ejemplo europeo contextualiza el retraso relativo español durante el último tercio del siglo XIX así como su progresiva homogenización vinculada al impacto de la guerra en el resto de Europa, y al propio dinamismo de las Cajas españolas durante la década de 1920. De esta forma, las magnitudes del sector en España tendieron a converger con la Europa más desarrollada en el período de entreguerras, con resultados definitivamente apreciables en los primeros años 30: véanse Cuadros 2 y 3.

\section{CUADRO 2}

MEDIAS QUINQUENALES DE LA RAZÓN

DEPÓSITOS DE LAS CAJAS DE AHORROS/ PIB, 1880-1935

(Porcentaje y a paridad de precios corrientes)

\begin{tabular}{|c|c|c|c|c|c|}
\hline & Francia & Gran Bretaña & Italia & Alemania & España \\
\hline $1880-1884$ & 6,5 & 6,8 & 8,2 & 16,9 & 0,7 \\
$1885-1889$ & 10,0 & 8,3 & 12,3 & 21,1 & 1,1 \\
$1890-1894$ & 13,1 & 8,9 & 14,4 & 23,7 & 1,5 \\
$1895-1899$ & 13,6 & 10,7 & 16,9 & 27,1 & 1,8 \\
$1900-1904$ & 13,4 & 10,8 & 17,9 & 30,9 & 2,3 \\
$1905-1909$ & 13,0 & 11,0 & 20,9 & 33,5 & 2,9 \\
$1910-1914$ & 11,8 & 11,1 & 22,3 & 29,5 & 3,8 \\
$1915-1919$ & & 6,9 & 16,3 & & 3,5 \\
$1920-1924$ & 4,7 & 7,8 & 16,3 & & 5,0 \\
$1925-1929$ & 6,8 & 9,8 & 17,4 & & 7,4 \\
$1930-1935$ & 17,8 & 9,2 & 31,1 & 18,3 & 11,3 \\
\hline
\end{tabular}

Fuente: Mitchell (1992) y Cuadro 1.

\footnotetext{
${ }^{22}$ Ibidem, y Martínez Soto (2000).
} 


\section{CUADRO 3}

\section{IMPONENTES POR 100 HABITANTES}

\begin{tabular}{|c|c|c|c|c|}
\hline & Francia & Gran Bretaña & Italia & España \\
\hline 1900 & 27,6 & 30,9 & 3,0 & 1,2 \\
1910 & 26,5 & 25,5 & 3,6 & 3,1 \\
1920 & 20,5 & 43,5 & 23,9 & 7,1 \\
1930 & 42,0 & 51,1 & 22,4 & 15,1 \\
\hline
\end{tabular}

Fuente: Mitchell (1992) y Cuadro 1.

En España, el incremento del ahorro popular, además de contar con el impulso institucional, mantuvo estrecha relación con factores como la oleada de fundaciones de organizaciones agrarias registrada durante el primer tercio de siglo XX -especialmente el ingente número de Cajas de Ahorro y Rurales vinculadas a sindicatos agrarios creadas durante la primera década del siglo-, así como con el incremento general de la renta. Si en un primer momento -de 1840 a 1880- la mayor parte de las Cajas habían sido fundadas a instancias de oligarquías y corporaciones locales, así como figuras o asociaciones religiosas, entre 1890 y 1936 alrededor del $40 \%$ de las fundaciones estuvieron relacionadas con este tipo de asociacionismo generalmente católico, que, junto a las corporaciones locales y centros obreros -también ligados a la Iglesia-, constituyeron el grueso de la promoción de las Cajas y Montes ${ }^{23}$. El cooperativismo agrario imitó el ejemplo de otros países europeos en lo cuales su crecimiento solía vincularse a la existencia de instituciones propias de microcrédito para suministrar recursos productivos a sus socios. Fue sobre todo entre 1915 y 1935 cuando se produjo el mayor impulso del crédito agrícola unido a la creación de Cajas Rurales y de Ahorros, en relación con la modernización agraria y el crecimiento de las pequeñas y medianas empresas industriales. Todo ello arrancó con la Ley de Asociaciones de 1887, que regulaba y reconocía las entidades de previsión, los socorros mutuos y las cooperativas, además de favorecer la creación de un buen número de Cajas ligadas a organizaciones agrarias -Cámaras agrícolas, Sindicatos, etc. Con posterioridad, la Ley de Sindicatos de 1906 impulsó el desarrollo del cooperativismo agrario, y, ligado a ello, se desarrolló un número importante de Cajas de Ahorro y Rurales. Finalmente, tras la Primera Guerra Mundial el cooperativismo experimentó su mayor auge,

${ }^{23}$ Vid. Forniés (1991, pp. 45-46). 
destacando la fundación de sindicatos y entidades de crédito en Navarra, Valencia, Cataluña, Aragón y Castilla-León ${ }^{24}$.

Por otra parte, el incremento del nivel de vida en España fue sensiblemente mayor desde 1920, a través de un aumento significativo de las tasas de empleo y renta $^{25}$. La evolución de los depósitos de ahorro de las Cajas en relación con el PIB (Gráfico 1) muestra un aumento paralelo, aunque mucho mayor, de los primeros -entre 1920 y 1935 el ahorro creció anualmente a tasas sensiblemente superiores al $7 \%$ mientras que el PIB/c lo hizo al 1,1. Esta tendencia se vio favorecida por el mayor número de entidades y su rápida expansión territorial, que permitió captar el pequeño ahorro existente. El valor de las imposiciones medias evolucionó a un ritmo mucho menor que el observado por el conjunto del ahorro, cuando no decreciente, lo que muestra la incidencia del incremento del número de impositores a través de un sistema con un número cada vez mayor de entidades y oficinas. Las imposiciones medias permanecieron relativamente estables entre las 600 y 750 pesetas hasta 1920, creciendo hasta las 1.080 pesetas en 1935. La expansión del ahorro popular fue paralela a la de la banca privada, aunque en este caso son más visibles los efectos de la coyuntura, sobre todo los referidos a la guerra y posguerra mundial así como a la crisis internacional de $1930^{26}$.

Por otra parte, la expansión del ahorro de las Cajas influyó de una manera importante sobre el conjunto del sistema financiero, en especial por lo que se refiere al comportamiento de las entidades bancarias. En 1882 el Banco de Bilbao abrió su propia Caja de Ahorros y, desde la primera década del siglo XX, un número cada vez mayor de bancos hicieron lo mismo, con objeto de entrar en el mercado en expansión del pequeño ahorro. Es decir, junto a la acción corporativa de la banca privada por condicionar el crecimiento de las Cajas en su propio beneficio, también se produjo una competencia en términos de oferta de servicios financieros. La desagregación del ahorro de las Cajas permite observar con mayor claridad esta cuestión (Cuadro 4). El incremento continuado de las cuentas de ahorros de toda clase de Cajas fue evidente, con especial relevancia de las benéficas, cuyos depósitos llegaron a suponer, en vísperas de la guerra civil, entre

\footnotetext{
${ }^{24}$ Véase Terrón (1987) para los aspectos legislativos, así como los trabajos de Garrido (1996) y Martínez Soto (2003a) sobre el sindicalismo y el cooperativismo agrario de crédito español durante el primer tercio del siglo XX.

${ }^{25}$ Vid. Martínez Carrión (2002), Bringas (1997), Ballesteros (1997) y Quiroga (2001).

${ }^{26}$ Para el análisis e interpretación de la expansión bancaria durante el primer tercio del siglo XX existen numerosas referencias, entre las que cabe destacar: Tedde (1974) y (2001), Roldán, García Delgado y Muñoz (1973), Muñoz (1978 y 1988), Belford (1979), García Ruiz (1999), González (1999), Palafox (1991) y Arroyo (2003). Sobre la presencia de la banca extranjera en España en esas fechas, véanse Tedde (1974), Arroyo (1999) y García Ruiz (2001).
} 


\section{GRÁFICO 1}

ÍNDICES DE PIB PER CÁPITA, SALARIOS Y DEPÓSITOS DE

AHORRO DE CAJAS Y BANCOS (Pesetas constantes de 1935. 1935=100)

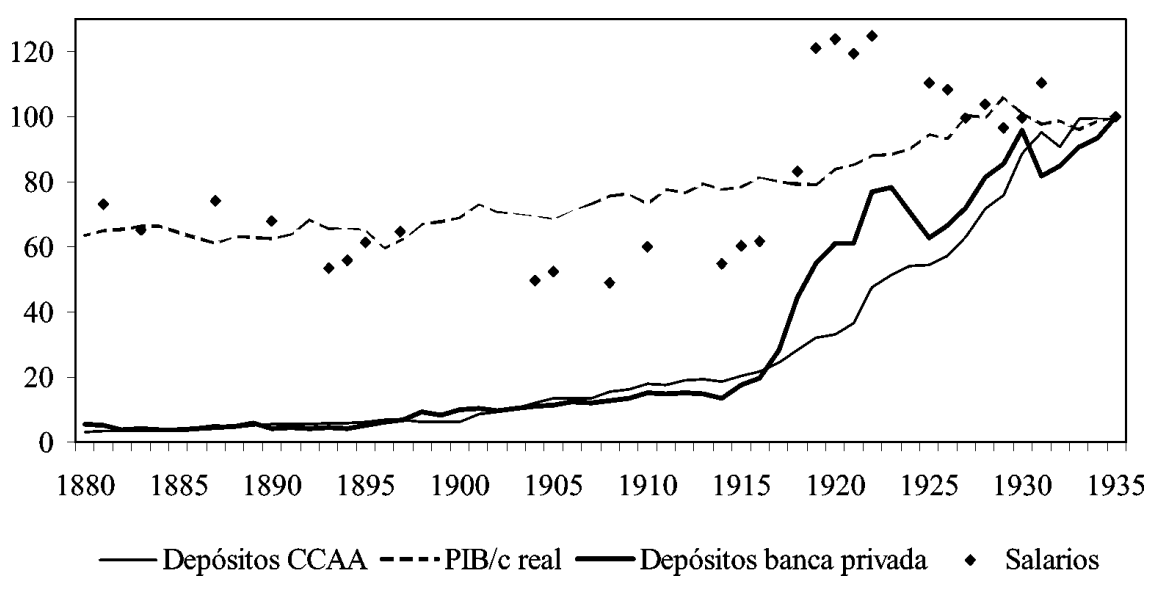

Fuentes: Cuadro 3, Bringas (1997), Prados (2000) y Carreras (ed.) (1989).

el 7 y el 8\% de la Renta Nacional frente al 2\% anterior a 1920. Las entidades dependientes de la banca privada crecieron de forma notable durante los primeros años del siglo XX, representando por encima del 30\% del líquido del ahorro de las Cajas en los años previos a la Primera Guerra Mundial ${ }^{27}$. Los efectos del conflicto internacional sobre la economía española contribuyeron al incremento de los recursos ajenos de la banca privada a un ritmo superior al de las Cajas y, por supuesto, al del Banco de España, fenómeno respaldado en la expansión de su red de sucursales. Menos significativa resultó ser la cuota de participación de la Caja Postal, inferior al 10\% de los depósitos totales, logrando su mayor expansión entre 1925 y 1929. En resumen, la evolución general de las Cajas españolas durante la Restauración y hasta la guerra civil muestra su consolidación como un elemento primordial del sistema financiero, además de su definitiva singularización frente a la banca privada.

\footnotetext{
${ }^{27}$ Tortella (1974, p. 499).
} 


\section{CUADRO 4}

\section{DISTRIBUCIÓN DE LOS DEPÓSITOS EN EL SISTEMAFINANCIERO ESPAÑOL Y EN CAJAS DE AHORRO, SEGÚN TIPO, 1880-1935 (Porcentajes)}

\begin{tabular}{|c|c|c|c|c|c|c|c|}
\hline & \multirow{2}{*}{$\begin{array}{l}\text { Banco de } \\
\text { España } \\
\text { Cuentas } \\
\text { corrientes }\end{array}$} & \multirow{2}{*}{$\begin{array}{c}\text { Banca } \\
\text { privada } \\
\text { (cc }+ \\
\text { depósitos) }\end{array}$} & \multirow{2}{*}{$\begin{array}{c}\text { Banca } \\
\text { privada } \\
\text { (cc+dep } \\
+ \text { c. ahorro) }\end{array}$} & \multirow{2}{*}{$\begin{array}{l}\text { Cajas de } \\
\text { Ahorros } \\
\text { (A) }\end{array}$} & \multicolumn{3}{|c|}{ Tipos de Cajas } \\
\hline & & & & & $\begin{array}{l}\text { CC. AA. } \\
\text { Benéficas } \\
\text { (\% A) }\end{array}$ & $\begin{array}{l}\text { CC. AA. de } \\
\text { Banca Pri- } \\
\text { vada (\% A) }\end{array}$ & $\begin{array}{l}\text { Caja } \\
\text { Postal } \\
\text { (\% A) }\end{array}$ \\
\hline $1880-84$ & 45,74 & 36,77 & 37,43 & 17,50 & 92,8 & 7,2 & - \\
\hline 1885-89 & 56,62 & 27,13 & 29,34 & 16,25 & 90,7 & 9,3 & - \\
\hline $1890-94$ & 56,89 & 22,95 & 26,14 & 20,16 & 83,8 & 16,2 & - \\
\hline 1895-99 & 56,88 & 26,51 & 30,23 & 16,61 & 77,9 & 22,1 & - \\
\hline $1900-04$ & 49,34 & 31,19 & 35,68 & 19,47 & 76,9 & 23,1 & - \\
\hline 1905-09 & 36,74 & 38,62 & 47,26 & 24,64 & 65,1 & 34,9 & - \\
\hline $1910-14$ & 30,15 & 41,51 & 51,34 & 28,34 & 65,3 & 34,7 & - \\
\hline 1915-19 & 28,67 & 50,52 & 55,63 & 20,82 & 71,3 & 24,1 & 4,6 \\
\hline $1920-24$ & 16,60 & 61,79 & 67,60 & 21,61 & 65,7 & 26,7 & 7,6 \\
\hline $1925-29$ & 12,64 & 59,23 & 67,57 & 28,13 & 61,9 & 29,4 & 8,7 \\
\hline $1930-35$ & 8,84 & 57,75 & 68,40 & 33,41 & 61,8 & 31,4 & 6,9 \\
\hline
\end{tabular}

Fuente: Cuadro 1 y Carreras (ed.) (1989).

La expansión de las Cajas resulta relevante no sólo en sí misma, sino también por sus efectos inducidos sobre el sistema bancario. Como se ha señalado, un buen número de bancos orientó parte de sus esfuerzos a captar el ahorro de las clases medias y asalariadas de carácter urbano, imitando la oferta de las Cajas. Este fenómeno se desarrolló a través de dos mecanismos complementarios. Por un lado, determinados bancos fundaron sus propias Cajas de Ahorros, formalmente dependientes de la entidad pero con cierta autonomía de gestión. Esto se produjo en aquellas ciudades en la cuales la expansión de las Cajas benéficas era importante, tratando con ello de restarle parte de su clientela. En esos casos (Cuadro 5) la proporción de los depósitos de la Caja de Ahorros representó más de un tercio de los pasivos exigibles -llegando a más del $60 \%$ en entidades como el Banco de Santander o el de Vitoria. Por otro lado, encontramos numerosos bancos de menor tamaño que no crearon una caja bancaria vinculada, sino que desarrollaron una sección de Caja de Ahorros o Caja de Economías con el mismo fin (Cuadro 6). En este caso, también la proporción de los depósitos era significativa. Todo ello constituye un factor más a tener en cuenta para explicar la consolidación de la banca nacional durante la década de 1920. Estos mecanismos, además poco estudiados, 
sólo pueden ser verificados mediante la investigación sobre entidades específicas, y muestran la capacidad de respuesta de la oferta bancaria frente a los cambios del mercado potencial. La consolidación bancaria a través de las sucursales debió tener estrecha vinculación con la atención a ese mercado del pequeño ahorro, sobre todo en cuanto a los bancos de tamaño medio o pequeño cuyas redes de oficinas eran regionales y cuyo margen de crecimiento era más reducido que el de los grandes bancos nacionales: bancos del tipo del Santander, Valencia, Castellano, Oviedo, Mercantil, o de mayor tamaño, como el de Vizcaya y, sobre todo, el de Bilbao.

\section{CUADRO 5}

\section{BANCOS CON CAJADE AHORROS. DISTRIBUCIÓN DE SUS DEPÓSITOS, 1921 (Pesetas)}

\begin{tabular}{|l|r|r|c|}
\hline & $\begin{array}{r}\text { Depósitos en Caja } \\
\text { de Ahorros }\end{array}$ & Total Depósitos & \% \\
\hline Banco de Vitoria & 15.021 .791 & 23.301 .817 & 64,5 \\
Banco Santander & 22.979 .255 & 38.262 .412 & 60,1 \\
Banco del Comercio & 23.819 .713 & 47.539 .596 & 50,1 \\
Banco Castellano & 21.758 .925 & 44.719 .220 & 48,7 \\
Banco Mercantil & 56.997 .120 & 117.275 .343 & 48,6 \\
Banco Asturiano & 13.908 .521 & 29.790 .732 & 46,7 \\
Crédito Unión Minera & 41.010 .210 & 91.429 .115 & 44,9 \\
Banco Vasco & 6.443 .179 & 14.904 .369 & 43,2 \\
Banco de Burgos & 5.973 .249 & 14.857 .352 & 40,2 \\
Banco Aragonés & 3.737 .739 & 9.522 .485 & 39,3 \\
Banco de Vizcaya & 49.460 .589 & 133.471 .877 & 37,1 \\
Banco de Gijón & 28.014 .586 & 79.111 .227 & 35,4 \\
Banco Herrero & 29.002 .677 & 88.494 .355 & 32,8 \\
Banco de Aragón & 22.115 .681 & 69.581 .857 & 31,8 \\
Banco de Bilbao & 50.194 .976 & 183.931 .419 & 27,3 \\
Banco Agrícola & 4.120 .019 & 19.594 .792 & 21,0 \\
Banco Riojano & 1.283 .415 & 6.526 .600 & 19,7 \\
Banco de la Coruña & 2.985 .708 & 18.001 .027 & 16,6 \\
Banco de Cartagena & 8.531 .865 & 55.613 .865 & 15,3 \\
B.UrquijoVascongado & 2.025 .487 & 16.623 .181 & 12,2 \\
Crédito Balear & 4.683 .477 & 43.321 .808 & 10,8 \\
Banco de Vigo & 938.226 & 26.725 .725 & 3,5 \\
\hline Total 22 bancos & $\mathbf{4 1 5 . 0 0 6 . 4 0 8}$ & $\mathbf{1 . 1 7 2 . 6 0 0 . 1 7 4}$ & $\mathbf{3 5 , 4}$ \\
\hline
\end{tabular}

Fuente: Anuario Financiero de Bilbao, Banco de Vizcaya, 1922. 


\section{CUADRO 6}

BANCOS SINCAJADEAHORROS, PEROCON SECCIÓN «CAJADE AHORROS» EN SUS DEPÓSITOS, 1921 (Pesetas)

\begin{tabular}{|l|r|r|r|}
\hline & $\begin{array}{r}\text { Depósitos en sección } \\
\text { de Caja deAhorros }\end{array}$ & Total Dep. & \% \\
\hline Banco de Reus (Caja de economías) & 6.788 .161 & 9.657 .932 & 70,3 \\
Banco de Valencia & 658.618 & 1.036 .543 & 63,5 \\
Banco Comercial de Tarragona & 5.550 .515 & 10.721 .522 & 51,8 \\
Banco de Tortosa (Caja de economías) & 1.840 .262 & 3.885 .763 & 47,4 \\
Fomento Agrícola de Mallorca & 1.731 .929 & 3.702 .779 & 46,8 \\
Banco de Torrelavega & 741.864 & 1.674 .711 & 44,3 \\
Banco de Ferrerías & 155.229 & 693.000 & 22,4 \\
Banco de Oviedo & 7.930 .943 & 37.520 .577 & 21,1 \\
Banco Agrario de Baleares & 218.881 & 1.200 .260 & 18,2 \\
Banco de Tarrasa & 1.140 .052 & 6.917 .803 & 16,5 \\
Fomento Agrícola, Industrial y Com. & 166.181 & 1.032 .081 & 16,1 \\
Banco Zaragozano & 1.427 .880 & 9.196 .965 & 15,5 \\
Crédito Mercantil Menorca & 317.023 & 2.513 .029 & 12,6 \\
Banco de Sóller & 935.748 & 9.262 .533 & 10,1 \\
Banco del Progreso Agrícola & 111.795 & 1.366 .742 & 8,2 \\
Banco de Cuenca & 47.330 & 731.706 & 6,5 \\
Banco de Felanitx & 223.671 & 3.627 .000 & 6,2 \\
Banco Minero-Industrial de Asturias & 600.529 & 12.161 .334 & 4,9 \\
Banco Popular de Manacor & 55.230 & 1.868 .413 & 3,0 \\
\hline Total 19 bancos & $\mathbf{5 7 . 0 1 9 . 6 5 3}$ & $\mathbf{1 6 3 . 4 8 9 . 9 1 3}$ & $\mathbf{3 4 , 9}$ \\
\hline
\end{tabular}

Fuente: Anuario Financiero de Bilbao, Banco de Vizcaya, 1922.

\subsection{La expansión del ahorro desde la perspectiva regional}

Una vez establecidos los rasgos generales de la expansión de las Cajas de Ahorros, se propone el enfoque regional de algunos aspectos relacionados, principalmente el reparto territorial de ahorro y el modus operandi de las propias Cajas, que contribuyen a explicar su expansión y consolidación. En primer lugar, el crecimiento del número de Cajas implicó un menor grado de concentración del sector a medida que se fundaron nuevas entidades y se redujo el peso proporcional de las pioneras, generalmente de las ubicadas en las grandes ciudades. Así pues, las Cajas 
tuvieron un comportamiento contrario al de los bancos privados, cuyo grado de concentración tendió a crecer durante el primer tercio del siglo XX. Las menores barreras de entrada en este sector con respecto a los bancos influyó en este fenómeno, ya que la impronta territorial de las Cajas -sellada legalmente- disminuía la competencia entre ellas a la hora de establecer sucursales. Tanto en número de imponentes como en depósitos, la importancia de las cinco mayores Cajas tendió a descender con respecto al total: de un $90 \%$ del total de ahorro representado por las cinco grandes en 1885, se pasó al 53\% en 1935, fenómeno paralelo al acaecido con la proporción de imponentes (Cuadro 7).

Un segundo aspecto se refiere a la distribución territorial del ahorro en España, que resulta relativamente conocido y coincidente con lo sucedido en la banca priva$\mathrm{da}^{28}$. Desde finales del siglo XIX, las Cajas andaluzas tendieron a desaparecer de la relación de las mayores entidades, en consonancia no sólo con el declive económico regional sino también con la especialización productiva que favorecía más la actividad de la banca privada y con el escaso desarrollo del cooperativismo agrario $^{29}$. Paralelamente, a partir de la primera década del siglo XX se produjo la consolidación del polo financiero vasco, incluidas sus Cajas, mientras que también resulta destacable el descenso relativo de la Caja de Ahorros de Madrid, la mayor entidad por depósitos en las décadas finales del siglo XIX, en relación con el auge de los grandes bancos privados en la capital ${ }^{30}$. Fue, sin embargo, en Cataluña donde las Cajas tuvieron un mayor desarrollo - a diferencia de lo ocurrido con la gran banca privada-, de manera que, en 1935, tanto la Caja de Pensiones como la de Barcelona eran las mayores de España en cuanto a captación de ahorro, inaugurando una tendencia persistente durante prácticamente todo el siglo XX. Finalmente, la Caja de Ahorros de Valencia se mantuvo como una de las cinco grandes, hecho vinculado a su importancia demográfica y económica y a la ausencia de una banca privada propia más allá del Banco de Valencia y los banqueros particulares.

Así pues, en 1935 se habían consolidado tres principales zonas en la captación de depósitos y número de entidades e imponentes: Cataluña -agrupada en la CECAB con las Baleares y Aragón-, País Vasco-Navarra y las regiones de Valencia-Murcia (Federación de Levante). Paralelamente, en las regiones castellanas, con Madrid, y en Andalucía, las Cajas vieron descender su peso relativo en el conjunto del sistema. Regionalmente, por tanto, poco antes de la guerra civil el mercado del ahorro popular reflejaba la preeminencia de las clases asalariadas y medias de carácter urbano, así como de pequeños y medianos propietarios agrarios. Es decir, durante el primer tercio del siglo XX el reparto del ahorro siguió

\footnotetext{
${ }^{28}$ Tortella (1974); Tedde (1974).

${ }^{29}$ García Ruiz (2002).

${ }^{30}$ Tedde (1974 y 2001).
} 
unas pautas que respondían a la localización de las actividades económicas más acordes con las posibilidades de financiación de las Cajas, vinculadas básicamente a las economías domésticas.

\section{CUADRO 7}

\section{EVOLUCIÓN DE LOS DEPÓSITOS DE LAS CINCO MAYORES CAJAS Y SU PROPORCIÓN RESPECTOAESPAÑA}

\begin{tabular}{|l|c|r|l|r|r|l|r|r|}
\hline \multicolumn{3}{|c|}{1885} & \multicolumn{3}{c|}{1915} & \multicolumn{3}{c|}{$\mathbf{1 9 3 4}$} \\
\hline & Millones & $\mathbf{9}$ & & Millones & \% & & Millones & \% \\
\hline Madrid & 43,1 & 59,4 & Barcelona & 58,0 & 16,2 & Caixa & 570,8 & 23,4 \\
Barcelona & 10,8 & 14,9 & Madrid & 54,8 & 15,3 & Barcelona & 290,2 & 11,9 \\
Sevilla & 8,5 & 11,7 & Valencia & 41,0 & 11,4 & Bilbao & 180,1 & 7,4 \\
Valencia & 2,7 & 3,7 & S. Sebastián & 33,2 & 9,3 & Guipúzcoa & 145,3 & 6,0 \\
Jerez & 0,9 & 1,2 & Bilbao & 27,6 & 7,7 & Valencia & 116,9 & 4,8 \\
\hline Total & & & Total & & & Total & & \\
Cajas & $\mathbf{7 2 , 6}$ & $\mathbf{9 0 , 9}$ & Cajas & $\mathbf{3 5 8 , 4}$ & $\mathbf{5 9 , 9}$ & Cajas & $\mathbf{2 . 4 3 9 . 0}$ & $\mathbf{5 3 , 4}$ \\
España & & & España & & & España & & \\
\hline
\end{tabular}

Fuente: CECA (1986-1987).

Las Cajas de Ahorros agrupadas en la Federación de Levante iniciaron su andadura con la fundación de la Caja de Ahorros y Socorros de Murviedro (Sagunto) en 1841 y de la Caja-Banco (Caja de Ahorros y Monte de Piedad) en Valencia en $1842^{31}$. De estas dos entidades iniciales tan sólo se mantuvo en activo la primera. La Caja-Banco de Valencia desapareció en 1852 por la conjunción de factores que terminaron por colapsar su funcionamiento, básicamente, por la dificultad de colocación de los depósitos de ahorro y los efectos de la crisis de 1847/48. Después de estas primeras instituciones, las fundaciones se volvieron a poner en marcha en el último tercio del siglo XIX con la creación de las Cajas de Ahorros y Monte de Piedad de Alcoy (1875), Alicante (1877) y Valencia (1878), que supusieron el inicio de la extensión de este tipo de entidades en la región valenciana. En Murcia el

${ }^{31}$ Al respecto de su fundación y funcionamiento, véase Ródenas (1978), Tortella (1973) y Hernández Sempere (1983). 
proceso fue algo más lento -la primera entidad apareció en 1893 en Jumilla- y, además, las Cajas Rurales se adelantaron a las urbanas, ya que éstas -las de Murcia y Cartagena- se fundaron al inicio de la década de 1920. Es decir, en términos generales primero surgieron las entidades urbanas y de mayor tamaño orientadas al crédito a las clases populares urbanas y asalariadas, sobre todo en el País Valenciano, en relación además con la existencia de grupos sociales promotores. Las entidades más pequeñas y de carácter agrario se desarrollaron posteriormente, durante los dos primeros decenios del siglo XX, ligadas a la expansión del asociacionismo agrario ya reseñada.

\section{CUADRO 8}

COMPOSICIÓN REGIONAL DE LA CECAB, 1932

\begin{tabular}{|c|c|c|c|c|}
\hline \multirow[b]{2}{*}{ Federación Regional } & \multirow[b]{2}{*}{$\begin{array}{l}\text { Número } \\
\text { de Cajas }\end{array}$} & \multicolumn{3}{|c|}{ Depósitos de ahorro } \\
\hline & & $\begin{array}{c}\text { Capital } \\
\text { impuesto } \\
\text { (millones } \\
\text { pesetas) }\end{array}$ & $\begin{array}{c}\text { Imposición } \\
\text { media/ } \\
\text { caja (mill. } \\
\text { pesetas) }\end{array}$ & $\begin{array}{c}\text { \% Total de } \\
\text { las Cajas } \\
\text { CECAB }\end{array}$ \\
\hline Vasco-Navarra & 8 & 583,32 & 73 & 27,3 \\
\hline Galicia & 7 & 62,38 & 9 & 2,9 \\
\hline Castellana & 6 & 61,09 & 10 & 2,8 \\
\hline Asturiana & 3 & 24,01 & 8 & 1,1 \\
\hline Oeste de España & 6 & 64,56 & 11 & 3,0 \\
\hline Levante & 20 & 224,15 & 11 & 10,5 \\
\hline Catalano-Aragonesa-Balear & 24 & 893,37 & 37 & 41,8 \\
\hline Andaluza & 7 & 39,08 & 5 & 1,8 \\
\hline Canarias & 2 & 19,18 & 9 & 0,9 \\
\hline Con representación propia* & 3 & 164,80 & 55 & 7,7 \\
\hline \multirow[t]{2}{*}{ Total CECAB } & 86 & $2.135,97$ & 25 & 100,0 \\
\hline & & & & $\begin{array}{c}\text { Capital CECAB / } \\
\text { total Cajas (\%) }\end{array}$ \\
\hline Total Cajas de Ahorros & 168 & $3.476,52$ & 21 & 61,4 \\
\hline
\end{tabular}

Fuente: Archivo Histórico del Banco de España, Sección Banca privada, Caja 80 y A.E.E. 1934.

Nota: * C.A. y M.P. de Madrid, C.A. de la Diputación Provincial de Ciudad Real, y M.P. y C.A. de León. 
Los períodos de mayor actividad correspondieron a los años 1886-1910, en que se creó un total de 25 Cajas, coincidiendo con el inicio de la expansión citrícola y otros cultivos de regadío, así como con la tendencia general expuesta para toda España. Este grupo de instituciones tuvo como rasgo distintivo su fuerte presencia en las principales zonas de agricultura comercializable y su estrecha relación respecto a sus grupos agrarios asociados y sectores de propietarios y de poder $^{32}$. Anteriormente habíamos señalado que, entre 1890 y 1939, el principal impulso promocional de las Cajas en España se debió a las organizaciones agrarias, y en buena parte este fenómeno se basó en el comportamiento de las entidades de Valencia y Murcia, que fueron las que mostraron un ritmo mayor de fundaciones. Entre 1890 y 1939, de las 62 Cajas promovidas en España por asociaciones y sindicatos agrarios, 27 (45\%) lo fueron en aquellas regiones, lo que muestra una clara especialización en la atención al sector agrario que complementó la acción de las entidades urbanas. Así pues, la consolidación en Valencia y Murcia de un grupo de Cajas con un peso importante en las finanzas regionales -sobre todo en contraste con su escasa actividad bancaria- debe explicarse, primero, por la expansión del mercado urbano del crédito vinculado a la creación de entidades en centros mercantiles y fabriles, aproximadamente hasta 1890/1900. A partir de esas fechas y hasta la década de 1920 el protagonismo lo asumieron las Cajas de las localidades agrarias, y su efecto principal fue la significativa contribución del ahorro regional en el conjunto nacional, cuyos valores máximos (15-17\%) se alcanzaron entre 1905 y 1920.

De forma general, en la región de Levante se distinguen tres tipos diferenciados de entidades: primeramente, las Cajas de Ahorros y Montes de Piedad ligados a patronatos; segundo, las Cajas de Ahorros dependientes de organizaciones agrarias -Sindicatos, Asociaciones de agricultores, Cámaras Agrícolas, etc.-; y finalmente, las Cajas Rurales de Ahorros y Préstamos, dependientes de sindicatos agrícolas, cuyo funcionamiento se ajustaba a la Ley de 1906, aunque realizaban las mismas operaciones que las anteriores. Dentro de esta tipología, las primeras operaban en los núcleos mayores -Valencia, Alicante, Alcoy, Cartagena, Murcia, Elche y Castellón-, aunque en ocasiones una proporción significativa de la clientela era de procedencia mayoritariamente agraria, como en la de la última de las citadas. La función central de todas ellas fue la captación del ahorro de forma especializada y, en menor medida, la de banca al por menor. El cumplimiento de su cometido fue posible porque reunían una serie de condiciones entre las que destacaba la delimitación de su espacio físico de actuación, la cual constituyó una estrategia eficaz al limitar los riesgos de las operaciones, debido al control y al mayor conocimiento directo de la clientela, así como a la confianza ligada a su carácter benéfico.

\footnotetext{
${ }^{32}$ Sobre el papel desempeñado por las Cajas de Ahorros en el desarrollo de la agricultura valenciana y murciana hasta la I Guerra Mundial veánse Martínez Soto (1994) y Cuevas (2001).
} 


\section{CUADRO 9}

\section{EVOLUCIÓN DEL NÚMERO DE CCAA BENÉFICAS Y DEPÓSITOS DE AHO- RRO DE VALENCIA Y MURCIA Y CUOTA DE PARTICIPACIÓN EN EL CONJUNTO DE CAJAS BENÉFICAS DE ESPAÑA, 1880-1935}

(Pesetas constantes de 1995)

\begin{tabular}{|c|c|c|c|c|c|c|}
\hline Años & $\begin{array}{c}\text { CC.AA.B. } \\
\text { Levante }\end{array}$ & $\begin{array}{c}\text { \% de } \\
\text { España }\end{array}$ & Años & $\begin{array}{c}\text { Depósitos CC.AA.B. } \\
\text { España } \\
\text { (miles pesetas) }\end{array}$ & $\begin{array}{c}\text { Depósitos CC.AA.B. } \\
\text { Levante } \\
\text { (miles pesetas) }\end{array}$ & $\%$ \\
\hline 1880 & 5 & 19,2 & $1880-84$ & 683.292 & 18.064 & 2,6 \\
1885 & 8 & 22,2 & $1885-89$ & 920.931 & 61.831 & 6,7 \\
1890 & 9 & 20,9 & $1890-94$ & 1.116 .899 & 119.666 & 10,7 \\
1895 & 9 & 20,9 & $1895-99$ & 1.307 .797 & 178.985 & 13,7 \\
1900 & 13 & 26,0 & $1900-04$ & 1.398 .317 & 239.719 & 17,1 \\
1905 & 24 & 33,3 & $1905-09$ & 1.864 .949 & 314.780 & 16,9 \\
1910 & 32 & 31,1 & $1910-14$ & 2.428 .083 & 430.438 & 17,7 \\
1915 & 34 & 30,4 & $1915-19$ & 3.592 .422 & 565.653 & 15,7 \\
1920 & 41 & 36,6 & $1920-24$ & 5.768 .696 & 881.366 & 15,3 \\
1925 & 45 & 23,1 & $1925-29$ & 7.865 .776 & 979.621 & 12,4 \\
1930 & 46 & 21,7 & $1930-35$ & 13.779 .636 & 149.709 & 10,9 \\
1935 & 47 & 21,2 & $1880-1935$ & 40.726 .802 & 5.287 .223 & 12,9 \\
\hline
\end{tabular}

Fuente: CC.AA. y MM.PP. de Levante: Memorias de Caja de Ahorros y Monte de Piedad de Madrid, Ceballos Teresí (1929) y Memorias de las entidades referidas. Series estatales de Cajas de Ahorros, ver Cuadro 1.

Para desarrollar esta fidelidad estimularon el ahorro y desplegaron una labor de integración en los circuitos financieros de los fondos captados. Las entidades ofrecían la posibilidad de invertir pequeños capitales con cierta rentabilidad, al tiempo que colocaban una parte importante de estas sumas en la atención a la demanda de numerario. La oferta de productos de ahorro de las Cajas se adaptó a las necesidades del mercado potencial, y creció a medida que las condiciones generales y financieras variaron. Así, desde el siglo XIX las Cajas desarrollaron diferentes formas de ahorro libre o voluntario, diferenciadas en cuanto a los límites y los mínimos de las imposiciones, cuyo objetivo común fue el de consolidar la clientela y hacer frente a la creciente competencia de la banca. Entre las primeras -ahorro libre-, destacaron por su importancia las libretas de ahorro ordinario, preferente e ínfimo, libretas para recién nacidos, infantiles y escolares, así como cuentas corrientes, de ahorro a medio y largo plazo y los sellos de ahorro. Entre el ahorro mutualista destacaron a su vez el ahorro mutuo y obrero-estatal, las imposiciones voluntarias para pensiones, 
las de retiro y las de subsidio de maternidad. Finalmente, durante los primeros años del siglo XX aparecieron nuevos servicios de ahorro vinculados al desarrollo de medidas de protección social, bien a través del INP, bien por medio de iniciativas privadas $^{33}$.

Las Cajas de Ahorros desempeñaron un papel determinante en la canalización del ahorro y la inversión regionales, ya que tanto en Murcia como en Valencia la presencia de la banca privada ha sido históricamente muy reducida. La naturaleza de las actividades económicas principales, sea industria de bienes de consumo poco intensivas en capital, sea explotaciones agrarias familiares, no propició la aparición de entidades bancarias importantes. Al temprano desarrollo bancario valenciano ligado a los ferrocarriles de las décadas de 1850 y 1860, que acabó arrastrado por la crisis de 1864-66, siguió una aguda carencia de banca regional hasta los primeros años del siglo XX, tanto si nos fijamos en la expansión de sucursales de los bancos madrileños, vascos y extranjeros, como si atendemos a la expansión del Banco de Valencia. Además, hasta los primeros años del siglo XX buena parte de las demandas financieras eran atendidas por banqueros particulares, $y$, aunque se desconoce su incidencia exacta en el mercado financiero regional, su contribución fue significativa en servicios como el mantenimiento de cuentas corrientes, depósitos remunerados y, sobre todo, asistencia al crédito comercial ${ }^{34}$.

En general, los depósitos de las Cajas levantinas fueron superiores a los de la banca privada -en sus modalidades de cuentas de depósitos y ahorros y cuentas corrientes-, aunque su participación mayoritaria en el conjunto regional fue descendiendo de forma progresiva: si, hacia finales del siglo XIX, las Cajas dominaban el ahorro regional casi sin competencia, hacia 1935 ya sólo concentraban el 60\% del mismo. Durante el período considerado, el incremento medio anual del ahorro en la región se situó sensiblemente por encima del 10\%, ligado en gran medida a la comercialización de productos agrarios cuyos beneficios se canalizaron a través de las entidades financieras, así como, en menor medida, a las actividades industriales.

\footnotetext{
${ }^{33}$ Sobre los primeros pasos de las Cajas españolas en la configuración del sistema de protección y retiro obrero durante el primer tercio del siglo XX, véase Sudrià (1998).

${ }^{34}$ No se puede estimar el volumen del ahorro que podían movilizar las casas particulares de banca hasta los primeros años del siglo $\mathrm{XX}$, aunque existen trabajos en torno al papel que desempeñaron en la financiación de actividades productivas tanto en Valencia como en Murcia: véanse Hernández Sempere (1996), Cuevas (2002) y Arroyo (2000). Para la estructura bancaria anterior, vid. nota 31. Existen, sin embargo, evidencias sobre el número de oficinas en 1922, que muestran una hegemonía de la banca particular en ambas regiones. En esa fecha, las 17 oficinas de la banca nacional ubicadas en Valencia y las 4 de Murcia representaban alrededor del 10\% de las que funcionaban en ambas regiones, frente a un 77 y un $72 \%$, respectivamente, de las bancas particulares, aunque estas proporciones seguramente no serían representativas para el volumen de recursos movilizados. En Murcia la mayor red de sucursales correspondía al Banco de Cartagena -9 concretamente, un 16\%-, cuya implantación explica en parte la tardanza de la aparición de las Cajas de Ahorros de Murcia y Cartagena.
} 
La notable implantación de pequeñas entidades de ahorro popular y rural les permitía ofrecer sus servicios a los productores con ventaja sobre la banca privada, que no contaba con una red de sucursales tan amplia como para llegar a numerosas localidades de tamaño medio con gran dinamismo agrario. Además de esta diferenciación espacial, se produjo una especialización operativa, ya que, mientras las Cajas de Ahorro se especializaron en proporcionar insumos y asistencia dineraria a los pequeños y medianos productores -propietarios o no-, la banca privada se encargó de facilitar la comercialización final a los exportadores y grandes propietarios a través del giro mercantil en cuenta.

La especialización de la oferta financiera actuó también en el seno de las mismas Cajas de Ahorros, como se observa a través de la evolución del valor medio de las imposiciones. Se ha recogido un grupo de Cajas diferenciando entre las que operaban en ámbitos urbanos -capitales de provincia y núcleos mercantiles o fabriles-y las que lo hacían en ciudades cuya actividad económica se desarrollaba alrededor de la agricultura, generalmente intensiva (Cuadro 10). Los valores de las imposiciones en las Cajas urbanas siempre fueron mayores que los correspondientes a las localidades agrarias, lo que es indicativo de su diferente clientela. La de las primeras incluye categorías socioprofesionales -pequeños industriales, artesanos, asalariados, profesionales liberales, funcionarios, etc.- con rentas mayores que las de los impositores de las segundas -jornaleros, pequeños arrendatarios, pequeños y medianos propietarios, etc.

Otro elemento que distingue a la especialización de las entidades se refiere a la estacionalidad del ahorro y del préstamo, cuya concentración preferente en determinados meses indica los condicionantes productivos de las economías, concretamente las rurales. En este caso, el comportamiento de su clientela estaba estrechamente ligado a los ritmos y calendarios de los cultivos y su comercialización, mientras que el de la clientela de las entidades urbanas era más aleatorio y uniforme. La estacionalidad en las operaciones ilustra la función social del ahorro mutualista en una región de notable dinamismo económico, ligado desde la mitad del siglo XIX a la comercialización agraria. La estacionalidad de las operaciones de ahorro -concentradas generalmente entre enero y abril, el período de mayores ingresos para pequeños y medianos propietarios, enfiteutas y colonos- muestra que las Cajas situadas en las localidades agrarias constituyeron un elemento clave en la financiación a corto plazo de la actividad productiva. La posibilidad de convertir el ahorro en adelantos de insumos -semillas, compra de abonos, anticipos de cosecha y pago de rentas-resultaba esencial en economías familiares con una fuerte estacionalidad de los ingresos y, en última instancia, contribuyó al acceso a la propiedad de la tierra de grupos de arrendatarios no propietarios ${ }^{35}$. De igual forma actuó la estacionalidad

${ }^{35}$ Véase Cuevas (2001, p.100). 


\begin{tabular}{|c|c|c|c|c|c|}
\hline \multirow{13}{*}{ 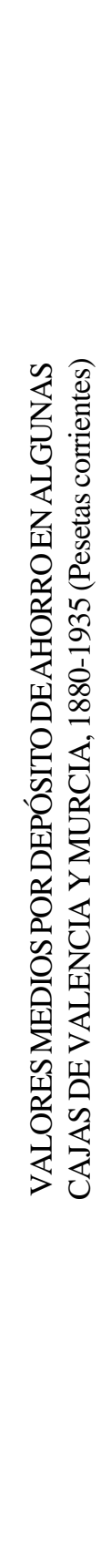 } & $\begin{array}{l}\stackrel{0}{0} \\
\stackrel{9}{二}\end{array}$ & 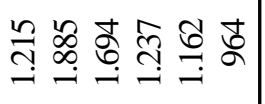 & 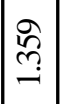 & 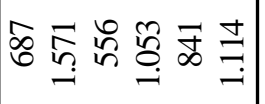 & হু \\
\hline & $\stackrel{\mathscr{\tilde { \sigma }}}{\sigma}$ & 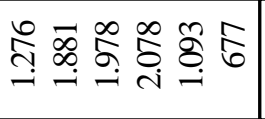 & $\stackrel{\text { gq }}{-}$ & 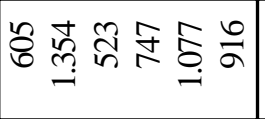 & $\stackrel{?}{\infty}$ \\
\hline & $\begin{array}{l}\stackrel{\mathfrak{N}}{\sigma} \\
\stackrel{-}{-1}\end{array}$ & 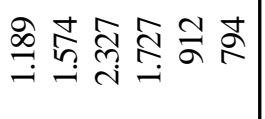 & $\stackrel{\text { भ̊ }}{\stackrel{\sim}{-}}$ & 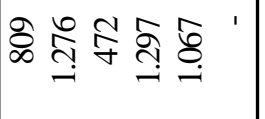 & $\stackrel{d}{a}$ \\
\hline & 六 & 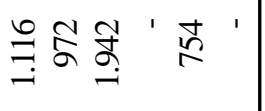 & $\stackrel{\mathscr{Q}}{\mathscr{H}}$ & 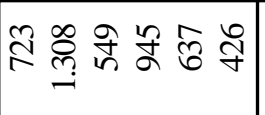 & 늘 \\
\hline & 늠 & 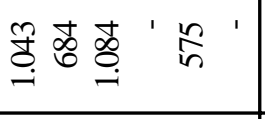 & $\begin{array}{l}0 \\
\infty \\
\infty\end{array}$ & 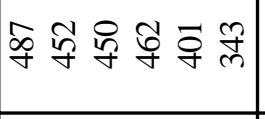 & $\tilde{\vartheta}$ \\
\hline & 음 & 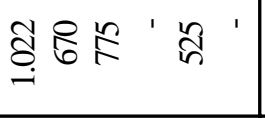 & $\frac{9}{1}$ & 荫 & $\stackrel{m}{m}$ \\
\hline & 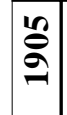 & 若 & $\bar{R}$ & 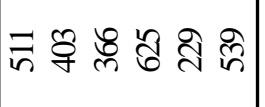 & $\mathscr{f}$ \\
\hline & ఫે & 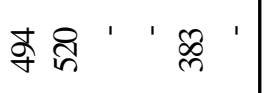 & 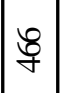 & $\hat{م}$ & $\overrightarrow{\mathrm{B}}$ \\
\hline & \begin{tabular}{l}
2 \\
$\infty$ \\
\hdashline \\
\hdashline
\end{tabular} & 婮余' ' & $\stackrel{\infty}{\mathscr{f}}$ & 串 ' ' & 命 \\
\hline & 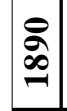 & \& 艼' '㣽' & 吕 & 8 ' ' స̃ & $\begin{array}{l}8 \\
\end{array}$ \\
\hline & \begin{tabular}{l}
$\mathbf{L}$ \\
$\infty$ \\
\hdashline \\
\hdashline
\end{tabular} & 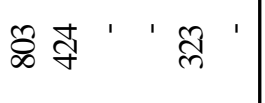 & in & of ' ' & 욱 \\
\hline & \begin{tabular}{l}
8 \\
$\infty$ \\
$\infty$ \\
\hdashline
\end{tabular} & $\stackrel{\infty}{=} \stackrel{\infty}{\prime}$ ' ' & ลิ & ' ' ' ' $\hat{m} \tilde{m}$ & $\ddot{n}$ \\
\hline & 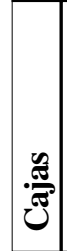 & 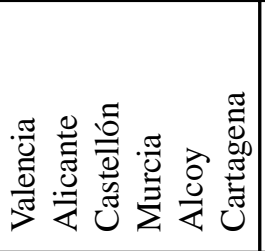 & $\mid \begin{array}{l}2 \\
\vdots \\
5 \\
\vdots \\
\vdots \\
5 \\
15\end{array}$ & 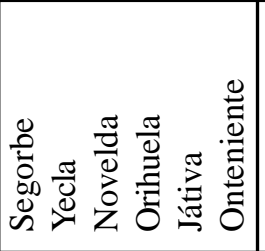 & 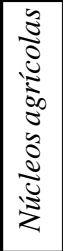 \\
\hline
\end{tabular}


del préstamo, consistente sobre todo en adelantos productivos, que se concentraba en los períodos de mayores necesidades financieras: la replantación, el abonado y la recolección. Durante los meses siguientes a las recolecciones, los pequeños campesinos debían resistir las presiones del mercado de productos agrarios y los procesos de «ventas desesperadas» en períodos de precios bajos ligados al endeudamiento usurario del mercado financiero informal. El flujo de préstamos garantizaba que los pequeños agricultores-propietarios pudieran vender sus producciones en los momentos de mayores precios al no tener que someterse a la lógica de la usura, mientras que, en el caso de los no propietarios, los préstamos resultaban esenciales para las economías familiares en época de migraciones temporeras. Así pues, el microcrédito predominante en el medio agrario español, aportado por las entidades de ahorro popular, se convirtió durante el primer tercio del siglo XX en una herramienta eficaz para que los pequeños campesinos titulares de las medianas y pequeñas explotaciones familiares pudiesen subsistir en el marco de agriculturas cada vez más especializadas.

\section{LA VERTIENTE INVERSORADE LAS CAJAS DE AHORROS}

Desde sus orígenes se produjo una vinculación estrecha entre las Cajas de Ahorros y los Montes de Piedad, ya que, en un primer período, los fondos de las primeras se destinaban en su totalidad a operaciones en el Monte, que debía devolver las cantidades percibidas con un módico interés. De esa forma, los préstamos con garantía pignoraticia dejaron de ser gratuitos. Como se señaló, la Ley de 1880 permitió fundar Cajas que no contasen con Monte de Piedad. Las entidades fundadas con esta nueva modalidad buscaron alternativas inversoras materializadas en nuevos tipos de préstamos, que tuvieron poco que ver con las tradicionales operaciones asistenciales de los Montes al dirigirse a grupos de mayor renta ${ }^{36}$. El crecimiento considerable de los recursos captados por las Cajas y la imposibilidad de los Montes para su colocación total provocó un cambio en los papeles que desempeñaban. Este hecho se produjo a partir de los últimos años del siglo XIX, pasando los Montes de Piedad durante el primer tercio del siglo XX a convertirse en meras secciones crediticias de las Cajas. La separación definitiva se asentó con el R.D.Ley de 9 de abril de 1926, cuya lógica residía en la pérdida de importancia de la inversión en los préstamos pignoraticios de los Montes. Finalmente, el Estatuto de 1933 señalaba a éstos como manifestación de la obra social de las Cajas, otorgándoles el carácter de «filiales» de aquéllas. Las Cajas, por su parte, tenían libertad para fijar las condiciones de la contratación, así como la proporción de las distintas operaciones respecto a sus depósitos.

\footnotetext{
${ }^{36}$ Fenómeno destacado anteriormente por Titos (1999).
} 
Desde estos presupuestos de partida se establecieron distintas relaciones entre las Cajas y los Montes, que en términos generales pueden resumirse en tres. En primer lugar, se encontraban las Cajas que consideraban al Monte como el centro de su operatoria, y que experimentaron un escaso desarrollo. Un segundo tipo lo constituían aquellas Cajas que entendían el Monte de Piedad como un servicio paralelo, prestando mayor atención a la operativa de la primera y al desarrollo de modalidades de crédito para la inversión de los depósitos. En este caso encontramos la doble dirección para contabilizar los créditos: unas incluían los préstamos hipotecarios, personales y sobre valores en la operatoria del Monte, y otras sólo comprendían en éste los préstamos sobre ropas, alhajas, enseres y valores. Finalmente, se encontraban las entidades que consideraban a los Montes de Piedad como una mera obra benéfico-social que apenas cubría gastos, haciéndose cargo de las operaciones que generaban plusvalías.

La evolución del capital prestado por los Montes de Piedad muestra una tendencia alcista en los últimos años del siglo XIX, aunque evidenció un descenso importante hasta la I Guerra Mundial, seguramente en relación con los efectos de la prolongada crisis finisecular en las economías más vulnerables. Pasada la coyuntura negativa -los niveles más bajos se observaron entre 1900 y 1910- tras la guerra el crecimiento fue intenso durante las décadas de 1920 y 1930, en consonancia con lo sucedido en las operaciones pasivas. Como se ha señalado, resulta destacable la relación entre el capital prestado por los Montes y la inversión de las Cajas de Ahorros: si durante el siglo XIX los préstamos representaban más de dos tercios de la inversión del pasivo de las Cajas, la proporción descendió paulatinamente hasta convertirse en una parte relativamente poco importante, alrededor del $20 \%$.

La pérdida progresiva de su importancia en las inversiones a partir del último quinquenio del siglo XIX debe relacionarse con la aparición de otro tipo de colocaciones, fundamentalmente la adquisición de valores y otras operaciones al margen de los préstamos prendarios. Las estrategias de créditos entre las décadas de 1920 y 1930 variaron de unas Cajas a otras, tanto en el capital anual destinado como en la preferencia por unas u otras modalidades de préstamo. Los tipos de interés tanto de los prendarios como de los restantes estuvieron en torno al $6 \%$ durante este período, aunque en la modalidad de los personales podían alcanzar el 7\%, lo cual permite hablar de una oferta relativamente barata en relación con la evolución de los precios. De esta forma, las nuevas modalidades, como los préstamos hipotecarios sobre fincas rústicas y urbanas, y los que se realizaban sobre garantías de títulos y acciones cotizables aumentaron su peso de forma sensible. Aunque no existen estadísticas de carácter general sobre la distribución del capital prestado, nuestras estimaciones realizadas sobre las diez mayores Cajas con información disponible para el período 1920-1933 reflejan que los préstamos hipotecarios concentraban la mayor parte del préstamo (un 62\%), seguidos de los préstamos propios del Monte de Piedad (24\%), y los que se realizaban sobre garantías de títulos y acciones, que 


\section{CUADRO 11}

\section{CAPITAL PRESTADO POR LOS MONTES DE PIEDADESPAÑOLES, 1880-1934 (Millones de pesetas constantes de 1935)}

\begin{tabular}{|l|c|c|c|}
\hline & $\begin{array}{c}\text { Montes de } \\
\left.\text { Piedad } \mathbf{( n}^{\mathbf{0}}\right)\end{array}$ & $\begin{array}{c}\text { Préstamos } \\
\text { (mill. ptas.) }\end{array}$ & $\begin{array}{c}\text { Inversión de } \\
\text { las Cajas (\%) }\end{array}$ \\
\hline $1880-1884$ & 29 & 535,6 & 78,4 \\
$1885-1889$ & 35 & 695,2 & 75,5 \\
$1890-1894$ & 36 & 780,7 & 69,9 \\
$1895-1899$ & 42 & 610,3 & 46,7 \\
$1900-1904$ & 43 & 353,7 & 25,3 \\
$1905-1909$ & 58 & 388,0 & 20,8 \\
$1910-1914$ & 62 & 524,3 & 21,6 \\
$1915-1919$ & 67 & 634,3 & 17,7 \\
$1920-1924$ & 94 & 999,5 & 17,3 \\
$1925-1929$ & 134 & $1.756,9$ & 22,3 \\
$1930-1934$ & 148 & $2.229,1$ & 19,8 \\
$1880-1934$ & - & $9.507,6$ & 24,9 \\
\hline
\end{tabular}

Fuente: Datos de A.E.E. confrontados con Memorias y Cuentas Generales del M. de P. y Caja de Ahorros de Madrid. Las cifras de MM.PP. corresponden al número de entidades que operó al final de cada quinquenio.

alcanzaron un significativo 12\%. El resto, menos del 2\%, correspondía a créditos personales ${ }^{37}$.

Las nuevas operaciones de crédito se orientaron hacia una clientela compuesta por profesionales urbanos, funcionarios, comerciantes e industriales, artesanos, etc., mientras que las clásicas operaciones de los Montes quedaron reservadas para los grupos sociales con menor capacidad de endeudamiento, en línea con lo que sucedía con la captación de pasivos. La ventaja en los intereses, más reducidos, de las Cajas frente a la banca privada constituyó un factor de expansión en el mercado de crédito en los estratos socioprofesionales reseñados. Esta situación se inició entre las entidades ubicadas en las grandes ciudades y capitales de provincia, aunque fue también en ellas donde tuvieron más funcionalidad las operaciones prendarias o pignoraticias realizadas a través de los Montes, atendiendo así los

\footnotetext{
${ }^{37}$ Razones obtenidas a partir de las memorias anuales de las Cajas de Alicante, Barcelona, Bilbao, Córdoba, Castellón, Coruña, León, Madrid, Orihuela, San Sebastián, Sevilla, Valencia, Vigo y Zaragoza. La diferencia de número se debe a las variaciones del ranking.
} 
problemas del pauperismo urbano. El incremento de los nuevos tipos de préstamos, especialmente los hipotecarios, estuvo en consonancia con el desarrollo urbanístico de las ciudades y los servicios públicos puestos en marcha entre 1920-1935, tal y como ya había sido señalado en términos más generales ${ }^{38}$. Por su parte, en las zonas agrarias las nuevas modalidades de crédito se orientaron de forma primordial a financiar la introducción de innovaciones en los cultivos o la adquisición de tierras.

\subsection{La inversión de las Cajas desde una perspectiva territorial}

Desde la óptica regional, la organización del crédito respondió a la misma diferenciación que en el caso del ahorro. El análisis de las entidades de la Federación de Levante muestra que en los centros urbanos predominó el modelo de funcionamiento que consideraba las operaciones de los Montes como servicios «benéficos» destinados a las clases populares, mientras se reforzaban las otras líneas de crédito para clientes de mayor renta. Por otra parte, en las áreas rurales tanto del secano como del regadío los Montes de Piedad no existían en la práctica y, en su lugar, las Cajas realizaban directamente operaciones destinadas a atender la demanda de crédito de los productores a través de las modalidades hipotecaria, personal, y de inputs agrícolas -abonos y fitosanitarios- e incluso basadas en la «prenda sin desplazamiento» -modalidad de crédito introducida en España a principios del siglo XX, en la que la garantía quedaba en manos del prestatario. La peculiaridad de las Cajas de Valencia y Murcia con respecto al resto de España fue que su inversión en préstamos tuvo una dimensión menor, al menos al principio (véase Cuadro 12). En 1885-1889 los préstamos sólo suponían un tercio de la inversión total de las Cajas, proporción que descendió hasta menos del 10\% entre 1900 y 1910. Esta circunstancia puede ser indicativa de los efectos de la crisis finisecular, en especial sobre la agricultura regional y sus inversiones de capital. Este proceso cambió a partir de 1915-1919, debido al crecimiento y extensión de las tierras destinadas a los cítricos y cultivos en los regadíos, que redobló las demandas de capital de los cultivadores con el consecuente incremento de la oferta de créditos. En conjunto, entre 1880 y 1934 la participación de las Cajas levantinas en el crédito concedido por el conjunto de entidades del país a través de los Montes de Piedad fue del 15,7 \%. Como se ha indicado, hasta 1915 la participación de las entidades de Valencia y Murcia no estuvo acorde con sus cifras de ahorro y de número de Cajas, ya que la proporción del capital prestado osciló entre el 2,4 y el 6,9 \%. La participación de los Montes levantinos se incrementó considerablemente en los años comprendidos entre 1910 y 1934, alcanzando el máximo en el quinquenio 1925-1929, con el 24,8 \%

\footnotetext{
${ }^{38}$ Tedde (2001, p.161).
} 
del total del capital prestado por todo el sistema. Estas cifras de préstamos y su peso dentro del conjunto de las inversiones deben ser tomadas con precaución, ya que muchas de ellas no utilizaban los Montes de Piedad como medio de canalizar su labor crediticia, sino que operaron directamente a través de las nuevas modalidades de préstamo. El peso de las mayores Cajas como Valencia, Alicante Alcoy o Murcia explica dicha circunstancia.

\section{CUADRO 12}

CAPITAL PRESTADO POR LOS MONTES DE PIEDAD DE LAFEDERACIÓN DE LEVANTE, 1880-1934 (Millones de pesetas constantes de 1935)

\begin{tabular}{|c|c|c|c|c|c|}
\hline & \multicolumn{2}{|c|}{ Montes de Piedad } & \multirow{2}{*}{$\begin{array}{l}\text { Capital prestado } \\
\text { por las Cajas de } \\
\text { la Feder. Levante }\end{array}$} & \multirow{2}{*}{\begin{tabular}{|c|} 
Inversión \\
realizada por \\
las mismas (\%)
\end{tabular}} & \multirow{2}{*}{$\begin{array}{l}\text { Total prestado } \\
\text { por las Cajas } \\
\text { españolas (\%) }\end{array}$} \\
\hline & $\begin{array}{c}\text { Feder. } \\
\text { Levante }\end{array}$ & $\begin{array}{c}\text { \% de } \\
\text { España }\end{array}$ & & & \\
\hline $1880-04$ & 8 & 27,5 & 12,7 & 70,3 & 2,4 \\
\hline 1885-89 & 10 & 28,5 & 19,3 & 31,2 & 2,7 \\
\hline $1890-94$ & 11 & 30,5 & 24,2 & 20,2 & 3,1 \\
\hline 1895-99 & 11 & 26,1 & 22,7 & 16,2 & 3,7 \\
\hline $1900-04$ & 20 & 46,5 & 21,9 & 9,1 & 6,2 \\
\hline 1905-09 & 22 & 37,9 & 26,8 & 8,5 & 6,9 \\
\hline $1910-14$ & 24 & 38,7 & 84,0 & 19,5 & 16,0 \\
\hline 1915-19 & 28 & 41,7 & 131,1 & 23,2 & 20,7 \\
\hline $1920-24$ & 31 & 32,9 & 222,8 & 25,3 & 22,3 \\
\hline $1925-29$ & 31 & 23,1 & 436,1 & 44,5 & 24,8 \\
\hline $1930-34$ & 32 & 21,6 & 520,6 & 41,8 & 23,5 \\
\hline 1880-1934 & - & - & $1.499,5$ & 29,7 & 15,7 \\
\hline
\end{tabular}

Fuente: Elaborado a partir de A.E.E., Ceballos Teresí (1929) y de las Memorias y Cuentas Generales del M. P. y C. A. de Madrid. Los M. P. se corresponden a los existentes al final de cada quinquenio en las provincias de Castellón, Valencia, Alicante y Murcia.

Como se indicó, la mayor parte de las Cajas de Ahorro de Valencia y Murcia fueron fundadas por organizaciones agrarias y tenían una clientela con una extracción socioprofesional estrechamente ligada a la actividad en este sector y más concretamente a la agricultura de regadío. El tradicional funcionamiento de los Montes de Piedad no se ajustaba a las necesidades de la agricultura comercializable, lo que 
obligó a las Cajas a introducir modificaciones en sus operaciones de crédito a través del establecimiento de modalidades prendarias nuevas -con garantía en productos agrícolas- o prescindiendo del Monte de Piedad. De esta forma, además de los tradicionales préstamos con garantía personal, hipotecaria o de valores, se establecieron tipos de préstamo nuevos, como los corporativos, los avalados con garantía de productos agrícolas, maquinaria y aperos, así como cuentas de crédito con garantía personal e hipotecaria.

Por otra parte, las Cajas urbanas como las de Valencia, Alicante o Alcoy tuvieron un comportamiento más ajustado al patrón general para todo el país, es decir, con un funcionamiento del Monte basado en las tradicionales prendas -alhajas y ropas- y en otras alternativas de crédito más capaces de absorber mayor cantidad de capital -hipotecarios, personales, cuentas corrientes de crédito con garantías hipotecarias, etc., que se convirtieron en la alternativa a la función del Monte de Piedad y cuyos destinatarios eran la capas medias urbanas. La distribución del capital prestado por la Caja de Ahorros y Monte de Piedad de Valencia demuestra que, desde aproximadamente 1900, estas modalidades, que escapaban a la acción del Monte, ganaron terreno en la actividad crediticia de la entidad hasta convertirse rápidamente en el principal vehículo de la colocación de capitales, junto con el aumento de los valores en cartera. Así, además de los hipotecarios sobre fincas destinados a la construcción de edificios y mejoras en los existentes, ganaron importancia los préstamos a comerciantes e industriales sobre valores públicos y privados, cuentas corrientes de crédito con garantía personal y de la misma categoría con garantía hipotecaria, así como préstamos con garantía de productos agrícolas. En estos casos, los valores medios eran mayores, oscilando entre las 500 y las 25.000 pesetas, aunque, excepcionalmente, la Caja pudo aumentar tales límites. Los préstamos sobre valores fueron los menos frecuentes, debido a que las garantías estaban expuestas a las oscilaciones del mercado.

La misma situación se repite en otras Cajas urbanas que también trabajaron con una clientela prestataria más amplia. Esta circunstancia se vio favorecida por el ya citado escaso desarrollo de la banca privada en estas ciudades. El caso de Alicante resulta significativo, ya que, entre 1920 y 1925, sólo contó con tres sucursales de bancos -Central, Español de Crédito y Cartagena-, dos casas de banca locales, y la sucursal del Banco de España. Este escenario favoreció la expansión de la caja alicantina -fundada en 1877- en la captación de depósitos, posibilitando la ampliación de su oferta crediticia destinada a las nuevas modalidades de préstamos. Así, el capital invertido por la entidad en préstamos hipotecarios y personales creció de manera sostenida desde 1906, hasta el punto de que, a partir de 1921, éstos constituyeron el eje de sus créditos llegando a representar más del 75\% del capital otorgado durante la década de $1920^{39}$. El retraso de la banca privada regional-que además

${ }^{39}$ Memoria(s) Anual(es) de la Caja de Ahorros y Monte de Piedad de Alicante. 
debió afrontar la crisis de exportación agraria de la Primera Guerra Mundial-propició que el dominio de las Cajas en cuanto a la captación de depósitos tuviera correspondencia también en la financiación de actividades productivas a través de las operaciones de crédito. Los criterios que manejaron las entidades para la concesión de préstamos diferían mucho de unas a otras, tanto en el volumen destinado como en la utilización de los diferentes tipos de crédito. Es decir, se produjo una progresiva diversificación de las modalidades crediticias y un peso cada vez mayor de las de carácter hipotecario, destinadas a favorecer el desarrollo de la pequeña propiedad, y pudiendo considerarse al tiempo como un mecanismo de ayuda a las economías domésticas y como un factor de financiación empresarial. Su importancia destaca, además, por la histórica debilidad que el crédito hipotecario a largo plazo había tenido en la operatoria de la banca privada en España, a excepción de los prestamistas particulares. Las Cajas fueron las únicas instituciones que realmente practicaron este tipo de préstamos más allá del Banco Hipotecario que tenía este privilegio, buscando con ello la seguridad de sus inversiones ${ }^{40}$.

Un ejemplo complementario de canalización de recursos financieros hacia la agricultura se encuentra en los préstamos concedidos por Montes de Piedad dependientes de entidades vinculadas a asociaciones agrarias. Este fenómeno fue muy frecuente ya que, en ese caso, los Montes no actuaban como entidades de beneficencia sino como verdaderas instituciones de crédito agrario. Así pues, los Montes de Piedad ligados a las entidades agrarias eran sólo testimoniales y subsistían sobre el papel para evitar quedarse al margen de la legislación vigente. Generalmente no realizaban los tradicionales empeños de ropa y alhajas, sino operaciones crediticias más adecuadas a la demanda: operaciones de crédito sobre insumos, préstamos personales, hipotecarios, y mantenimiento de cuentas de crédito con garantía hipotecaria ${ }^{41}$. Esta circunstancia hacía que los importes medios de los créditos concedidos por las Cajas de localidades vinculadas a la agricultura comercial superasen con mucho la media nacional, lo que muestra una demanda diferenciada. Algunas instituciones captaban la mayor parte de su clientela entre los pequeños y medianos propietarios que manejaban producciones destinadas a la exportación con alto valor añadido. Junto a este fenómeno, no puede olvidarse la propia capacidad de adaptación de las Cajas de Ahorros, cuya flexibilidad operativa propició su expansión en el medio agrario.

${ }^{40}$ J. Sardá y L. Beltrán reflejaban esta situación en 1933: «El crédito hipotecario es uno de los terrenos en que las tendencias monopolizadoras del Estado español más daño ha hecho [...] solamente las cajas de ahorros, sin buscar un lucro más importante, sino la seguridad de sus inversiones, se han dedicado en gran escala al crédito hipotecario». Cfr. Nadal y Sudriá (1982, p. 249).

${ }^{41}$ Esta diferenciación entre las operaciones tradicionales de empeño de los Montes y las nuevas operaciones de crédito que realizan las cajas al margen de los primeros ha sido resaltada por Forniés (1989, pp. 63-68) para el conjunto del país. 
En última instancia, el esfuerzo de las Cajas y Montes por ampliar la naturaleza de sus operaciones, así como por adaptar la oferta crediticia a su mercado principal, fue respaldado por la acción corporativa de la CECAB. Su aparición en 1928 permitió a las entidades confederadas la coordinación de esfuerzos para mejorar el funcionamiento y seguridad de las operaciones de los Montes. Así, la CECAB realizó gestiones para que, en 1929, las Cajas obtuvieran del Sindicato General de las Compañías de Seguros contra Incendios unas condiciones especiales en pólizas para cubrir las contingencias de las operaciones prendarias. También trató de mediar ante el Gobierno con motivo de la promulgación del R.D. de 21-XI-1929, que reglamentaba la industria y comercio con metales preciosos y que afectaba a los préstamos sobre alhajas. Otra actuación que resultó relevante, sobre todo para las Cajas que operaban en ámbitos agrarios, se concreta en la elaboración de la ponencia de la V Asamblea de la Confederación (1932) que estableció una regulación común de los préstamos sin desplazamiento de prenda.

Una última cuestión a observar en cuanto a la acción inversora de las Cajas se refiere a la compra de valores, como se sabe, una de las alternativas más utilizadas por las entidades, al tiempo que más reguladas por la Administración. Las Cajas que no disponían de Monte de Piedad o que sobrepasaban sus demandas de crédito invirtieron sus recursos ajenos en valores, según el criterio establecido por sus consejos de administración y, en general, constituyeron carteras bastante diversificadas. Como se indicó, la legislación de 1926 y sucesivas obligaban a las Cajas a tener en su cartera valores públicos por un porcentaje que osciló entre el 50 y el 30\% de los saldos de ahorro, de cuya cantidad la mitad se destinaría a la compra de Deuda Perpetua al 4\%. Estas directrices introdujeron cambios en la composición de las carteras de valores de las entidades, aunque no en cuanto a la importancia de esta vertiente inversora presente desde el siglo XIX, ya que la legislación limitó la variedad de títulos a adquirir, e imposibilitaba la adquisición de acciones de compañías extranjeras.

La inversión en valores públicos había sido una constante en la trayectoria de las Cajas de Ahorros en España, circunstancia que no puede desvincularse de la relativa seguridad y rentabilidad de estas operaciones así como de la relativa estrechez del mercado inversor doméstico ${ }^{42}$. La adquisición de valores se convirtió en el centro de la estrategia inversora de las grandes Cajas urbanas, ya que, por encima de los coeficientes obligatorios, éstas continuaron colocando buena parte de sus recursos ajenos en este tipo de operaciones con carácter voluntario. Esto se puede comprobar a través de la actuación de entidades como

${ }^{42}$ Debe resaltarse, sin embargo, que la aplicación de los coeficientes legales no fue estricta debido sobre todo a la falta de control y supervisión por parte del Gobierno. 
la Caja de Pensiones para la Vejez de Barcelona o la Caja de Ahorros y Monte de Piedad de Valencia (Gráfico 5). En general, los títulos estatales tuvieron un papel hegemónico en las carteras de todas las Cajas, aunque en las grandes ciudades también se produjo una importante inversión en valores locales -deuda municipal y provincial-, que ofrecían más garantías que los títulos ferroviarios. También en este caso la acción de la CECAB resultó destacable, ya que desempeñó el papel de oficina intermediadora de las Cajas asociadas en la compra de deuda pública, función que, desde 1933, pasó al ICCA ${ }^{43}$.

\section{CUADRO13}

INVERSIÓN OBLIGATORIADE LAS CC.AA. BENÉFICAS EN VALORES

DEL ESTADO, 1926-1935 (Millones de pesetas constantes de 1935)

\begin{tabular}{|c|c|c|}
\hline & $\begin{array}{c}\text { Inversión obligatoria } \\
\text { de los depósitos en } \\
\text { valores del Estado }\end{array}$ & $\begin{array}{c}\text { Inversión teórica } \\
\text { en deuda perpetua } \\
\text { al 4 \% }\end{array}$ \\
\hline 1926 & 613,4 & 122,7 \\
1927 & 616,4 & 123,3 \\
1928 & 684,6 & 136,9 \\
1929 & 680,3 & 136,1 \\
1930 & 777,7 & 155,5 \\
1931 & 854,2 & 170,8 \\
1932 & 895,8 & 179,2 \\
1933 & 982,5 & 196,5 \\
1934 & 995,2 & 199,0 \\
1935 & 1006,4 & 201,3 \\
\hline
\end{tabular}

Fuente: Elaborado a partir del coeficiente obligatorio de inversión en valores del Estado fijado por la legislación.

${ }^{43}$ Los Estatutos del ICCA señalaban en su art. $5^{\circ}-3^{\circ}$ que las funciones del Instituto eran las de «Servir de intermediario en la negociación de valores que las Cajas le encomienden y concurrir a los empréstitos del Estado». 


\section{CONCLUSIONES}

Desde finales del siglo XIX, y en especial durante el primer tercio del siglo XX, las Cajas de Ahorros lograron asentar su posición dentro del sistema financiero español, superando los estrechos límites en que las encerraban sus orígenes como instituciones de beneficencia. Este cambio estuvo ligado a la especialización lograda por las entidades como «banca al por menor» a través de un amplio y flexible abanico de servicios que le permitió aumentar su clientela y atraer una parte mayor de las disponibilidades líquidas del país. Esta situación, no obstante, distaba de caracterizarse por una distribución territorial equilibrada, ya que la mayor penetración de las entidades coincidía con aquellas regiones que lograron un mayor desarrollo económico y que consecuentemente aumentaron su demanda de servicios. En todo caso, esta desigualdad regional no oculta el continuo crecimiento del sector durante este período, el cual tuvo como consecuencia la extensión del ahorro popular por todo el país a través de la fundación de nuevas Cajas y del incremento del volumen de depósitos de ahorro.

El contexto financiero-bancario nacional favoreció la extensión de las Cajas de Ahorros ya que, a inicios del siglo XX, la multitud de casas de banca privada existentes se dedicaba sobre todo a la prestación de unos servicios bancarios que no cabe tipificar como verdaderas operaciones financieras, mientras que la gran banca nacional no cubría -ni operativa ni territorialmente- la demanda de una buena parte de la población, principalmente en sus capas medias y bajas. Esta situación abría un amplio campo de actuación para las Cajas, que, a través del ahorro a la vista, lograron hacerse un hueco importante en el sistema financiero y fueron estableciendo estrategias de inversión con criterios de seguridad, liquidez y rendimiento asegurado. Lógicamente, esta política de colocación superaba los estrechos márgenes de los Montes de Piedad y favoreció la inversión en valores mobiliarios; en concreto, en fondos públicos, cuya seguridad estaba avalada por el Estado y cuya liquidez radicaba en sus posibilidades de pignoración o de venta rápida en el mercado de valores, al tiempo que su rendimiento satisfacía las necesidades de las entidades para retribuir los depósitos que tenían confiados.

La clientela mayoritaria de las Cajas de Ahorros era eminentemente popular, con una capacidad de generar ahorro limitada y, a la vez, con una exigencia de seguridad y garantías decididamente antepuesta a la búsqueda de rendimientos. Incluso cuando algunas de las Cajas más importantes, de carácter urbano, lograron atraerse a una clientela de superior estatus económico y con mayor capacidad de ahorro, también utilizaron esa política como elemento de atracción, con resultados bastantes efectivos. Este factor, unido a la diversificación y ampliación de sus servicios, explica el crecimiento continuado del número de impositores. Los recursos ajenos de las Cajas evolucionaron al alza durante todo el período estudiado, a pesar de las dificultades coyunturales, lo cual se relaciona con la confianza que estas entidades 
inspiraron a un amplio sector de la clientela potencial, es decir, el mercado de las economías domésticas. El crecimiento de los depósitos fue generalizado incluso en regiones afectadas por coyunturas adversas, como se comprueba en Valencia y Murcia durante las crisis de exportación de la Primera Guerra Mundial o los años treinta. Además, la adecuación de la oferta financiera representada por las Cajas al crecimiento de la demanda -en relación, sobre todo, con el incremento de la renta- queda demostrada por la competencia estratégica que la banca privada desplegó desde finales del siglo XIX por medio de sus secciones de 'Cajas de Ahorros' o servicios similares, que debieron ser claves en la expansión bancaria de la década de 1920.

El funcionamiento de las Cajas se vio sometido a una serie de regulaciones normativas que, iniciadas hacia 1880, se intensificaron desde 1926 y hasta 1935, abriéndose paralelamente el conflicto con los bancos por la captación de pasivos. La creación en 1921 del Consejo Superior Bancario permitió a la banca tener una influencia notable sobre el Ministerio de Hacienda y las decisiones relativas al sistema financiero, lo que tuvo su respuesta corporativa con la fundación, primero, de las Federaciones Regionales y, después, con la constitución de la CECAB. Estas actuaciones supusieron no sólo un freno a las pretensiones de la banca privada de controlar a las entidades benéficas y reducir su presencia, sino también un medio de representación colectiva frente al poder público. De esta forma, las Cajas pasaron a ser partícipes de las políticas sociales de los sucesivos gobiernos, al tiempo que contribuyeron a la financiación del Estado a través de las cuotas obligatorias de inversión en efectos públicos. Finalmente, la actuación de la CECAB fue también relevante para el funcionamiento interno de las entidades, al actuar como organismo coordinador y homogeneizador de sus operaciones.

\section{BIBLIOGRAFÍA}

Americi, L. (1997): «Les caisses d'épargne françaises face aux crises (1850-1914)», en L'histoire des caisses d'épargne européennes. Conjoncture et crises. París: les Éditions de l’Épargne, vol. 3, pp. 103-112.

Antón Ramízz, B. (1876): Montes de Piedad y Cajas de Ahorro. Reseña histórica y crítica. Origen, propagación, progresos y actual estado en España y el extranjero, conveniencia de generalizarlos en España y medios de conseguirlo. Madrid: Imprenta de Aribau y Cía.

Anuario Financiero de Bilbao. Bilbao: Banco de Vizcaya.

Anuario Financiero y de Sociedades Anónimas de España. Madrid: Sopec.

Arroyo, J. (1999): Actividad de la banca extranjera en España entre 1920 y 1935. Bilbao: BBV.

- (2000): La banca privada en Aragón, Valencia y Murcia entre 1920 y 1935. Bilbao: BBVA.

- (2003): La banca en España en el período de entreguerras, 1920-1935 (un modelo de modernización y crecimiento). Bilbao: BBVA. 
Ballesteros, E. (1999): «Retribuciones, poder adquisitivo y bienestar material de las clases populares. España y Castilla en la segunda mitad del siglo XIX», en J. Torras y B. Yun (dirs.), Consumo, condiciones de vida y comercialización. Cataluña y Castilla, siglos XVII-XIX. Ávila: Junta de Castilla y León, pp. 229-244.

Belford, N. (1979): «El sistema bancario durante la dictadura de Primo de Rivera». Cuadernos Económicos de ICE 10, pp. 227-266.

Bringas, M. A. (1997): «Un intento de reconstruir una variante del nivel de vida del campesinado: los salarios agrícolas en España, 1756-1935», en VII Congreso de Historia Agraria. Salamanca: Preactas SEHA, pp. 73-90.

Carreras, A. (ed.) (1989) Estadísticas históricas de España, siglos XIX-XX. Madrid: Fundación Banco Exterior.

Ceballos Teresí (1929): El libro del Ahorro. Las Cajas de Ahorros Benéficas en España. Madrid: Talleres Tipográficos de El Financiero.

- (1932) Historia económica, financiera y política de España en el siglo XX. Economía, finanzas y cambios. Madrid: El Financiero, vol. II.

CECA (1986a): Historia cuantitativa de las Cajas de Ahorros Españolas entre 1874-1900. Vol. 36. Madrid: Colección Estudios y Programación.

- (1986b) Historia cuantitativa de las Cajas de Ahorros Españolas en 1901-1927. Vol. 37. Madrid: Colección Estudios y Programación.

- (1987) Historia cuantitativa de las Cajas de Ahorros Españolas entre 1928-1935. Vol. 40. Madrid: Colección Estudios y Programación.

Comín, F. y Torres, E. (2003): «Historia urgente de la Confederación Española de Cajas de Ahorros». Papeles de Economía Española 97, pp. 246-284.

Cuevas, J. (2001): «La financiación del desarrollo agrario valenciano, 1750-1914». Historia Agraria 25, pp. 89-120.

- (2002): «Banking Growth and Industry Financing in Spain during the $19^{\text {th }}$ Century». Business History 44 (1), pp. 61-94.

Dictionnaire de l’Economie Politique (1973). París: Guillaumin et Cie.

Fernández SÁnchez, P. (2003): «El origen de la obra benéfica de las Cajas de Ahorros españolas (1839-1869)». Papeles de Economía Española 97, pp. 230-245.

FoRNIÉs CASALS, J. F. (1989): Las cajas de ahorros españolas en una etapa crucial de su historia: 1926-1939, Fuentes para la Historia de las Cajas de Ahorros y los Montes de Piedad españoles. Madrid: CECA, vol. 5.

- (1991): «Interpretación básica de la historia de las Cajas de Ahorros españolas». Papeles de Economía Española 46, pp. 39-51.

García Ruiz, J. L. (1999): «La nueva banca mixta en el Madrid de comienzos de siglo», en P. Tedde (ed.), Economía y colonias en la España del 98. Madrid: Síntesis, pp. 261-297.

- (2001): «La banca extranjera en España tras la Restauración, 1874-1936», en C. Sudrià, y D. Tirado (eds.), Peseta y Protección. Comercio exterior, moneda y crecimiento económico en la España de la Restauración. Barcelona: Edicions Universitat de Barcelona, pp. 197-220.

- (2002): «Los flujos financieros regionales en la España del siglo XX: Una perspectiva desde la historia bancaria». Asociación Española de Historia Económica, Documento de Trabajo ${ }^{\circ} 0201$.

GARRIDO, S. (1996): Treballar en comú. El cooperativisme agrari a Espanya (1900-1936). Valencia: IVIE. 
GonzÁLEz, M. J. (1999): «El Banco de Bilbao y el resurgir de la banca vizcaína a comienzos de siglo», en P. Tedde (ed.), Economía y colonias en la España del 98. Madrid: Síntesis, pp. 300-320.

González Moreno, J. M. (1983): Naturaleza y régimen jurídico de las Cajas de Ahorros. Madrid: Caja Madrid.

Grassi, P. (1997): «Les Caisses d’épargne en Italie. Des origines pré-unitaires à la première loi nationale (1822-1888)», en L'histoire des caisses d'épargne européennes. Conjoncture et crises.Vol. 3. París: les Éditions de l’Épargne, pp. 31-57.

Guinnane, T. (2001): «Delegated monitors, large and small: The development of Germany's Banking System». Yale University, Economic Growth Center. Discussion Paper no 835.

Hernández Sempere, T. (1983): Ferrocarriles y capitalismo en el País Valenciano, 18431879. Valencia: Ayuntamiento de Valencia.

- (1996): «Crédito y Banca privada en el período de consolidación del capitalismo en el País Valenciano (1840-1880)», en J. Azagra, E. Mateu y J. Vidal (eds.), De la Sociedad tradicional a la Economía moderna. Alicante: Estudios de Historia Valenciana Contemporánea, pp. 196-215.

InSTITUt INTERNATIONAL DE L’ÉPARgne (1935): Les Caisses d'Épargne dans le monde. Milán.

KRÜGER, I. (1997): «Caisses d'épargne et crises en Allemagne», en L'histoire des caisses d'épargne européennes. Conjoncture et crises. Vol. 3. París: les Éditions de l’Épargne, pp. 61-99.

Maixé J. C. (2001): «Las Cajas de Ahorros y el desarrollo económico balear». Estudis d'Història Econòmica 17-18, pp. 103-139.

Maixé, J. C., Vilar, M. y Lindoso, E. (2003): El ahorro de los gallegos. Orígenes e historia de Caixa Galicia (1876-2002). La Coruña: Fundación Caixa Galicia.

Martín AceñA, P. (1984): La política monetaria en España, 1919-1935.Madrid: I. E. F.

Martín Retortillo, S. (1975): Crédito, banca y cajas de ahorro. Madrid: Tecnos.

Martínez Carrión, J. M. (2002): «Nivel de vida en la España rural, siglos XVIII-XX. Nuevos enfoques, nuevos resultados», en J. M. Martínez Carrión (ed.), El nivel de vida en la España Rural, siglos XVIII-XX. Alicante: Publicaciones de la Universidad de Alicante, pp. 15-72.

Martínez Soto, A. P. (1994): «Crédito y Ahorro Popular. El Crédito Agrícola Institucional en la Región de Murcia (1850-1936)». Tesis Doctoral: Universidad de Murcia.

- (2000): «Las Cajas de ahorros españolas en el siglo XIX. Entre la beneficencia y la integración en el sistema financiero». Revista de Historia Económica XVIII (3), pp. 585-628.

- (2003a): «Los orígenes del cooperativismo de crédito agrario en España, 1890-1934». CIRIEC-España, Revista de Economía Pública, Social y Cooperativa 44, pp. 57-104.

- (2003b): «Las Cajas de Ahorros Españolas en el siglo XIX. Los orígenes del sistema (1839-1875)». Papeles de Economía Española 97, pp. 174-204.

Ministerio de Instrucción Pública y Bellas Artes, Dirección General del Instituto Geográfico y Estadístico (1916-1920): Anuario Estadístico de España. Madrid: Imprenta de los Sobrinos de la Sucesora de M. Minuesa de los Ríos.

Ministerio de Trabajo, Comercio e Industria, Dirección General de Estadística (1921-1934). Anuario Estadístico de España. Madrid: Establecimiento Tipográfico Sucesores de Ribadeneyra.

Mitchell, B. R. (1992): International Historical Statistics. Europe, 1750-1988. Hants: Macmillan. 
Moss, M. (1997): «L'exemple du Royaume-Uni (1850-1914) », en L'histoire des caisses d'épargne européennes. Conjoncture et crises.Vol. 3. París: les Éditions de l’Épargne, pp. 135-146.

MuÑoz, J. (1978): «La expansión bancaria entre 1919 y 1926. La formación de una Banca 'nacional'». Cuadernos económicos de ICE 6, pp. 98-162.

- (1988): «Banca e industrialización en el período 1900-1936», en Banca e industrialización en España. S.l.: Banesto, pp. 23-38.

Nadal, J. y Sudrià, C. (1983): Historia de la Caja de Pensiones. La Caixa dentro del sistema financiero catalán. Barcelona: Caixa - Edicions 62.

Palafox, J. (1991): Atraso económico y democracia. La II República y la economía española, 1892-1936. Barcelona: Crítica.

Pix, M. y Pohl, H. (dirs.) (1993): La diffusion de l'idée de Caisses d'Épargne Européennes. París: les Éditions de l’Épargne, vol. 2.

Prados de la Escosura, L. (2000): «Spain's gross domestic product, 1850-1990. A new series». Madrid: Ministerio de Economía, Documento de Trabajo D-93002.

Quiroga, G. (2001): «Estatura, diferencias regionales y sociales y niveles de vida en España (1893-1954)». Revista de Historia Económica XIX (1), pp. 175-200.

Ramos Bascuñana, R. (1910): La prenda agrícola o hipoteca inmobiliaria. Madrid: La Editora.

RóDENAs, C. (1978): Banca i industrialització. El cas valencià 1840-1880.Valencia: 3 i 4.

Roldán, S., García Delgado, J. L. y Muñoz, J. (1973): La formación de la sociedad capitalista en España, 1914-1920. Madrid: CECA, 2 vols.

Ros Pérez, F. (1996): Las Cajas de Ahorros en España. Evolución y régimen jurídico. Murcia: Universidad de Murcia - Caja Murcia.

Ross, D. (2001): «Penny banks and working class saving in Glasgow, 1850-1914». Savings Banks Conference $19^{\text {th }}-20^{\text {th }}$ September 2001. Centre for Business History in Scotland, University of Glasgow.

SARDÁ, J. (1970): «El Banco de España (1931-1962)», en El Banco de España. Una historia económica. Madrid: Banco de España, pp. 421-479.

SudriÀ, C. (1998): «Las Cajas de Ahorros en los orígenes del retiro obrero (1900-1939)». Papeles de Economía Española 74-75, pp. 323-330.

TedDE, P. (1974): «La banca privada durante la Restauración (1874-1914)», en La banca española durante la Restauración. Madrid: Servicio de Estudios del Banco de España, Vol. I, pp. 217-455.

- (1991): «La naturaleza de las Cajas de Ahorros: sus raíces históricas». Papeles de Economía Española 46, pp. 2-11.

— (2001): «El sistema financiero en la España del siglo XX», en A. Morales (coord.), Las transformaciones económicas. Madrid: Sociedad Estatal Nuevo Milenio, pp. 141-184.

TERRón, F. (1987): Las cajas rurales españolas: nacimiento, auge y perspectivas del cooperativismo agrario crediticio en España. Granada: Instituto de Desarrollo Regional de la Universidad de Granada.

Titos Martínez, M. (1991): «La respuesta histórica de las Cajas de Ahorros a las demandas de la sociedad española». Papeles de Economía Española 46, pp. 12-38.

- (1993): «Fondation et développement des Caisses d'Épargne en Espagne au XIXe siècle», en La diffusion de l'idée de Caisses d'Épargne Européennes. Vol. 2. París: les Éditions de l’Épargne, pp. 139-174. 
— (1999): «Las Cajas de Ahorros, 1853-1962» en P. Martín Aceña y M. Titos Martínez (eds.), El sistema financiero en España. Una síntesis histórica. Granada: Universidad de Granada, pp. 135-161.

- (2003a): «Las Cajas de Ahorros en España, 1835-1874. Orígenes, organización institucional y evolución financiera». Papeles de Economía Española 97, pp. 205-229.

- (2003b): El sistema financiero en Andalucía. Tres siglos de historia (1740-2000). Sevilla: Junta de Andalucía.

Titos Martínez, M. y Piñar Santos, J. M. (1983): Ahorro popular e inversión privilegiada. Las Cajas de Ahorros en España 1939-1975. Madrid: Caja de Madrid.

ToRTElla, G. (1973): Los orígenes del capitalismo en España. Banca, Industria y Ferrocarriles en el siglo XIX. Madrid: Tecnos.

- (1974): «Las magnitudes monetarias y sus determinantes», en La banca española durante la Restauración. Madrid: Servicio de Estudios del Banco de España, Vol. I, pp. 457-521.

Tortella, G. y Palafox, J. (1988): «Banca e industria en España, 1918-1936». Investigaciones Económicas 20, pp. 33-64.

Vellosillo, F. (1989): «La introducción de las ideas de las Cajas de Ahorros en España». Ponencia presentada al I Simposio de Historia de las Cajas de Ahorros y Montes de Piedad. Madrid: copia mecanografiada. 
APÉNDICE

\section{CUADROA1}

SERIE DE DEPÓSITOS DE LAS CAJAS DE AHORROS ESPAÑOLAS, 1850-1935 (Millones pesetas constantes de 1935)

\begin{tabular}{|c|c|c|c|c|c|c|c|}
\hline Años & $\begin{array}{c}\text { CC.AA. } \\
\text { Benéficas }\end{array}$ & $\begin{array}{c}\text { Total sistema } \\
\text { CC.AA. }\end{array}$ & Años & $\begin{array}{c}\text { CC.AA. } \\
\text { Benéficas }\end{array}$ & $\begin{array}{c}\text { CC.AA. de la } \\
\text { Banca Privada }\end{array}$ & $\begin{array}{c}\text { Caja } \\
\text { Postal }\end{array}$ & $\begin{array}{c}\text { Total sistema } \\
\text { CC.AA. }\end{array}$ \\
\hline 1850 & 15,8 & 15,8 & 1893 & 228,0 & & & 228,0 \\
1851 & 18,3 & 18,3 & 1894 & 237,9 & & & 237,9 \\
1852 & 20,1 & 20,1 & 1895 & 248,3 & & & 248,3 \\
1853 & 14,8 & 14,8 & 1896 & 279,6 & & & 279,6 \\
1854 & 15,6 & 15,6 & 1897 & 275,1 & & & 275,1 \\
1855 & 17,3 & 17,3 & 1898 & 251,5 & & & 251,5 \\
1856 & 22,0 & 22,0 & 1899 & 253,4 & & & 253,4 \\
1857 & 25,4 & 25,4 & 1900 & 250,8 & & & 250,8 \\
1858 & 28,0 & 28,0 & 1901 & 246,7 & 90,2 & & 336,9 \\
1859 & 29,5 & 29,5 & 1902 & 274,2 & 96,2 & & 370,4 \\
1860 & 32,5 & 32,5 & 1903 & 305,2 & 100,2 & & 405,3 \\
1861 & 35,3 & 35,3 & 1904 & 321,5 & 155,2 & & 476,7 \\
1862 & 37,0 & 37,0 & 1905 & 357,9 & 171,0 & & 528,9 \\
1863 & 37,1 & 37,1 & 1906 & 359,8 & 170,3 & & 530,1 \\
1864 & 36,8 & 36,8 & 1907 & 359,6 & 173,1 & & 532,8 \\
1865 & 38,6 & 38,6 & 1908 & 388,8 & 234,5 & & 623,3 \\
1866 & 33,9 & 33,9 & 1909 & 398,8 & 244,0 & & 642,8 \\
1867 & 34,0 & 34,0 & 1910 & 439,8 & 267,9 & & 707,7 \\
1868 & 35,7 & 35,7 & 1911 & 446,3 & 259,3 & & 705,6 \\
1869 & 27,0 & 27,0 & 1912 & 490,2 & 267,2 & & 757,4 \\
1870 & 30,2 & 30,2 & 1913 & 523,6 & 237,9 & & 761,5 \\
1871 & 34,3 & 34,3 & 1914 & 528,2 & 211,3 & & 739,6 \\
1872 & 36,5 & 36,5 & 1915 & 581,8 & 223,2 & & 805,0 \\
1873 & 30,6 & 30,6 & 1916 & 603,7 & 230,6 & 23,4 & 857,7 \\
1874 & 43,7 & 43,7 & 1917 & 698,0 & 235,0 & 46,9 & 979,9 \\
1875 & 60,2 & 60,2 & 1918 & 797,3 & 255,3 & 68,9 & $1.121,5$ \\
1876 & 75,8 & 75,8 & 1919 & 911,6 & 269,8 & 97,0 & $1.278,4$ \\
1877 & 84,1 & 84,1 & 1920 & 943,1 & 256,3 & 117,0 & $1.316,4$ \\
1878 & 102,3 & 102,3 & 1921 & $1.034,1$ & 271,7 & 141,0 & $1.446,8$ \\
1879 & 123,5 & 123,5 & 1922 & $1.177,0$ & 559,8 & 156,6 & $1.893,4$ \\
1880 & 128,1 & 128,1 & 1923 & $1.274,4$ & 596,2 & 174,7 & $2.045,2$ \\
1881 & 132,6 & 132,6 & 1924 & $1.340,1$ & 624,3 & 193,2 & $2.157,6$ \\
& & & & & & &
\end{tabular}


LA EXPANSIÓN Y CONSOLIDACIÓN DE LAS CAJAS DE AHORROS EN EL SISTEMA FINANCIERO

\section{CUADROA1 (continuación)}

SERIE DE DEPÓSITOS DE LAS CAJAS DEAHORROS ESPAÑOLAS, 1850-1935 (Millones pesetas constantes de 1935)

\begin{tabular}{|c|c|c|c|c|c|c|c|}
\hline Años & $\begin{array}{c}\text { CC.AA. } \\
\text { Benéficas } \\
0\end{array}$ & $\begin{array}{c}\text { Total sistema } \\
\text { CC.AA }\end{array}$ & Años & $\begin{array}{c}\text { CC.AA. } \\
\text { Benéficas }\end{array}$ & $\begin{array}{c}\text { CC.AA. de la } \\
\text { Banca Privada }\end{array}$ & $\begin{array}{c}\text { Caja } \\
\text { Postal }\end{array}$ & $\begin{array}{c}\text { Total sistema } \\
\text { CC.AA }\end{array}$ \\
\hline 1882 & 139,0 & 139,0 & 1925 & $1.379,0$ & 586,4 & 205,8 & $2.171,2$ \\
1883 & 136,6 & 136,6 & 1926 & $1.533,5$ & 511,9 & 226,6 & $2.271,9$ \\
1884 & 146,9 & 146,9 & 1927 & $1.541,0$ & 738,9 & 231,8 & $2.511,7$ \\
1885 & 160,3 & 160,3 & 1928 & $1.711,5$ & 881,7 & 255,3 & $2.848,4$ \\
1886 & 184,3 & 184,3 & 1929 & $1.700,8$ & $1.064,0$ & 251,3 & $3.016,2$ \\
1887 & 203,0 & 203,0 & 1930 & $1.944,3$ & $1.308,1$ & 273,9 & $3.526,2$ \\
1888 & 172,4 & 172,4 & 1931 & $2.135,5$ & $1.356,7$ & 294,7 & $3.787,0$ \\
1889 & 201,0 & 201,0 & 1932 & $2.239,6$ & $1.058,8$ & 309,9 & $3.608,3$ \\
1890 & 215,6 & 215,6 & 1933 & $2.456,2$ & $1.158,7$ & 336,6 & $3.951,5$ \\
1891 & 222,0 & 222,0 & 1934 & $2.488,1$ & $1.113,2$ & 345,2 & $3.946,5$ \\
1892 & 213,3 & 213,3 & 1935 & $2.516,0$ & $1.090,6$ & 368,9 & $3.975,5$ \\
\hline
\end{tabular}

Fuente: Anuarios Estadísticos de España, y Prados (2000). 


\section{CUADROA2}

SERIE DE PRÉSTAMOS DE LOS MONTES DE PIEDAD DE LAS

CAJAS DEAHORROS ESPAÑOLAS, 1880-1935

(Millones pesetas constantes de 1935)

\begin{tabular}{|c|c|c|c|}
\hline Años & Préstamos & Años & Préstamos \\
\hline 1880 & 105,4 & 1908 & 79,0 \\
\hline 1881 & 99,1 & 1909 & 84,1 \\
\hline 1882 & 111,2 & 1910 & 89,3 \\
\hline 1883 & 109,8 & 1911 & 86,3 \\
\hline 1884 & 110,0 & 1912 & 89,9 \\
\hline 1885 & 128,5 & 1913 & 125,5 \\
\hline 1886 & 128,0 & 1914 & 133,4 \\
\hline 1887 & 168,4 & 1915 & 128,3 \\
\hline 1888 & 112,1 & 1916 & 112,9 \\
\hline 1889 & 158,3 & 1917 & 127,4 \\
\hline 1890 & 132,7 & 1918 & 132,1 \\
\hline 1891 & 167,0 & 1919 & 133,5 \\
\hline 1892 & 157,0 & 1920 & 146,8 \\
\hline 1893 & 162,6 & 1921 & 157,7 \\
\hline 1894 & 161,5 & 1922 & 199,3 \\
\hline 1895 & 162,3 & 1923 & 210,8 \\
\hline 1896 & 175,0 & 1924 & 284,9 \\
\hline 1897 & 96,2 & 1925 & 308,3 \\
\hline 1898 & 90,2 & 1926 & 349,9 \\
\hline 1899 & 86,7 & 1927 & 363,2 \\
\hline 1900 & 75,1 & 1928 & 370,9 \\
\hline 1901 & 67,9 & 1929 & 364,5 \\
\hline 1902 & 71,2 & 1930 & 382,7 \\
\hline 1903 & 70,0 & 1931 & 433,9 \\
\hline 1904 & 69,4 & 1932 & 439,1 \\
\hline 1905 & 74,1 & 1933 & 469,4 \\
\hline 1906 & 77,6 & 1934 & 504,1 \\
\hline 1907 & 73,3 & 1935 & 496,6 \\
\hline
\end{tabular}

Fuente: Anuarios Estadísticos de España y Prados (2000). 